\title{
A buffered form of creatine does not promote greater changes in muscle creatine content, body composition, or training adaptations than creatine monohydrate
}

Andrew R Jagim¹, Jonathan M Oliver ${ }^{1,2}$, Adam Sanchez $^{1 \dagger}$, Elfego Galvan ${ }^{1 \dagger}$, James Fluckey ${ }^{3 \dagger}$, Steven Riechman ${ }^{4 \dagger}$, Michael Greenwood ${ }^{1 \dagger}$, Katherine Kelly ${ }^{5 \dagger}$, Cynthia Meininger ${ }^{5 \dagger}$, Christopher Rasmussen ${ }^{1 \dagger}$ and Richard B Kreider ${ }^{1 *}$

\begin{abstract}
Background: Creatine monohydrate (CrM) has been consistently reported to increase muscle creatine content and improve high-intensity exercise capacity. However, a number of different forms of creatine have been purported to be more efficacious than CrM. The purpose of this study was to determine if a buffered creatine monohydrate (KA) that has been purported to promote greater creatine retention and training adaptations with fewer side effects at lower doses is more efficacious than CrM supplementation in resistance-trained individuals.

Methods: In a double-blind manner, 36 resistance-trained participants $(20.2 \pm 2$ years, $181 \pm 7 \mathrm{~cm}, 82.1 \pm 12 \mathrm{~kg}$, and $14.7 \pm 5 \%$ body fat) were randomly assigned to supplement their diet with CrM (Creapure ${ }^{\circledR}$ AlzChem AG, Trostberg, Germany) at normal loading ( $4 \times 5 \mathrm{~g} / \mathrm{d}$ for 7 -days) and maintenance ( $5 \mathrm{~g} / \mathrm{d}$ for 21-days) doses; KA (Kre-Alkalyn ${ }^{\circledR}$, All American Pharmaceutical, Billings, MT, USA) at manufacturer's recommended doses (KA-L, $1.5 \mathrm{~g} / \mathrm{d}$ for 28-days); or, KA with equivalent loading ( $4 \times 5 \mathrm{~g} / \mathrm{d}$ for 7 -days) and maintenance $(5 \mathrm{~g} / \mathrm{d})$ doses of $\mathrm{CrM}(\mathrm{KA}-\mathrm{H})$. Participants were asked to maintain their current training programs and record all workouts. Muscle biopsies from the vastus lateralis, fasting blood samples, body weight, DEXA determined body composition, and Wingate Anaerobic Capacity (WAC) tests were performed at 0,7, and 28-days while 1 RM strength tests were performed at 0 and 28-days. Data were analyzed by a repeated measures multivariate analysis of variance (MANOVA) and are presented as mean \pm SD changes from baseline after 7 and 28-days, respectively.

(Continued on next page)
\end{abstract}

\footnotetext{
* Correspondence: rkreider@hlkn.tamu.edu

${ }^{\dagger}$ Equal contributors

'Department of Health and Kinesiology, Exercise and Sport Nutrition Laboratory, Texas A\&M University, College Station, TX 77843-4243, USA Full list of author information is available at the end of the article
} 
(Continued from previous page)

Results: Muscle free creatine content obtained in a subgroup of 25 participants increased in all groups over time $(1.4 \pm 20.7$ and $11.9 \pm 24.0 \mathrm{mmol} / \mathrm{kg} \mathrm{DW}, \mathrm{p}=0.03)$ after 7 and 28-days, respectively, with no significant differences among groups (KA-L $-7.9 \pm 22.3,4.7 \pm 27.0 ; \mathrm{KA}-\mathrm{H} 1.0 \pm 12.8,9.1 \pm 23.2 ; \mathrm{CrM} 11.3 \pm 23.9,22.3 \pm 21.0 \mathrm{mmol} / \mathrm{kg} \mathrm{DW}$, $p=0.46)$. However, while no overall group differences were observed $(p=0.14)$, pairwise comparison between the $\mathrm{KA}-\mathrm{L}$ and $\mathrm{CrM}$ groups revealed that changes in muscle creatine content tended to be greater in the CrM group $(\mathrm{KA}-\mathrm{L}-1.1 \pm 4.3, \mathrm{CrM} 11.2 \pm 4.3 \mathrm{mmol} / \mathrm{kg} \mathrm{DW}, \mathrm{p}=0.053$ [mean $\pm \mathrm{SEM}$ ]). Although some significant time effects were observed, no significant group $x$ time interactions ( $p>0.05$ ) were observed in changes in body mass, fat free mass, fat mass, percent body fat, or total body water; bench press and leg press 1RM strength; WAC mean power, peak power, or total work; serum blood lipids, markers of catabolism and bone status, and serum electrolyte status; or, whole blood makers of lymphocytes and red cells. Serum creatinine levels increased in all groups $(p<0.001)$ with higher doses of creatine promoting greater increases in serum creatinine $(p=0.03)$ but the increases observed $(0.1$ - $0.2 \mathrm{mg} / \mathrm{dl}$ ) were well within normal values for active individuals (i.e., $<1.28 \pm 0.2 \mathrm{mg} / \mathrm{dl}$ ). Serum LDL was decreased to a greater degree following ingesting loading doses in the CrM group but returned to baseline during the maintenance phase. No side effects were reported.

Conclusions: Neither manufacturers recommended doses of KA (1.5 g/d) or KA with equivalent loading (20 g/d for 7-days) and maintenance doses (5 g/d for 21-days) of CrM promoted greater changes in muscle creatine content, body composition, strength, or anaerobic capacity than CrM (20 g/d for 7-days, $5 \mathrm{~g} / \mathrm{d}$ for 21-days). There was no evidence that supplementing the diet with a buffered form of creatine resulted in fewer side effects than CrM. These findings do not support claims that consuming a buffered form of creatine is a more efficacious and/or safer form of creatine to consume than creatine monohydrate.

Keywords: Creatine monohydrate, Kre-Alkalyn, Training adaptations, Health, Safety

\section{Background}

Creatine has proven to be one of the most effective and popular dietary supplements for resistance-trained athletes [1-3]. The form of creatine that has been most extensively studied has been creatine monohydrate ( $\mathrm{CrM})$ [1]. Studies have consistently indicated that creatine supplementation increases muscle creatine and phosphocreatine concentrations by approximately 15-40\%, enhances anaerobic exercise capacity, and increases training volume leading to greater gains in strength, power, and muscle mass [1-10]. A number of potential therapeutic benefits have also been suggested in various clinical populations [11-17]. Studies have indicated that creatine monohydrate is not degraded during normal digestion and that nearly $99 \%$ of orally ingested creatine is either taken up by tissues or excreted in urine [18-20]. Further, no medically significant side effects have been reported in the literature [21-27]. Nevertheless, supplement manufacturers have continually introduced newer forms of creatine into the marketplace [1]. These newer forms have been purported to have better physical and chemical properties, bioavailability, efficacy, and/or safety profiles than creatine monohydrate [1]. However, there is little to no evidence that any of the newer forms of creatine are more effective and/or a safer form of creatine than CrM whether ingested alone and/or in combination with other nutrients [1]. In addition, whereas the safety, efficacy, and regulatory status of CrM is clearly defined in almost all global markets; the safety, efficacy and regulatory status of other forms of creatine present in today's marketplace as a dietary or food supplement is less clear [1].

A buffered form of creatine (Kre-Alkalyn ${ }^{\circledR}$ [KA], All American Pharmaceutical, Billings, MT, USA) has been marketed as a more efficacious and safer form of creatine than creatine monohydrate [28]. According to the manufacturer's website [28], this patented form of creatine [29] is a "buffered" or " $p H$-correct" form of creatine that remains more stable in the stomach, is not degraded to creatinine, and thereby has greater bioavailability. According to patent filings [29], this is accomplished by adding an alkaline powder (e.g., soda ash, magnesium glycerol phosphate, bicarbonate) to creatine (e.g., creatine monohydrate, creatine phosphate, creatine pyruvate, creatine citrate) in order to adjust the $\mathrm{pH}$ to a range between 7-14. The manufacturer claims that this form of creatine is "the only Creatine guaranteed to stay 100\% stable all the way to the muscle cell"; that it is "up to ten times more powerful than ordinary Creatine"; that "1.5 grams of Kre-Alkalyn is equivalent to about 10-15 grams of ordinary Creatine"; that it is "an alternative to all the bloating, cramping, and other side effects associated with traditional creatine supplementation"; and, that it is "the world's most potent creatine" [28]. The manufacturer cites several clinical studies on their website performed in Bulgaria to support their claims [28,30]. However, we could find no peer-reviewed articles cited in the National Library of Medicine's PubMed related to "Kre-Alkalyn", 
or "buffered creatine" from the purported study authors or anyone else. One paper that was presented at the International Society of Sports Nutrition annual meeting in 2007 reported that the conversion of creatine to creatinine from $\mathrm{CrM}$ at a $\mathrm{pH}$ of 1.0 and $37^{\circ} \mathrm{C}$ was less than $1 \%$ after 5, 30 and 120 minutes while KA had a 35\% greater conversion to creatinine under similar conditions [31]. However, full details of this study have yet to be published.

Our research group has extensive experience in conducting clinical research studies on the efficacy and safety of supplementing the diet during training with various forms of creatine [9,25,26,32-39]. As a result, AlzChem AG (Trostberg, Germany), a primary raw material provider of pure creatine monohydrate, provided a grant to our university to conduct an independent research study to compare the effects of supplementing the diet with KA at recommended doses $(1.5 \mathrm{~g} / \mathrm{d}$ for 28 days) and creatine equivalent loading (20 g/d for 7 -days) and maintenance doses (5 g/d for 21-days) of $\mathrm{KA}$ to CrM (20 g/d for 7-days, $5 \mathrm{~g} / \mathrm{d}$ for 21-days) on muscle creatine retention, body composition, strength, anaerobic capacity and markers of health status. We also sought to determine whether ingesting the purported buffered form of creatine would be associated with fewer side effects than creatine monohydrate as claimed. Theoretically, if KA is indeed a more efficacious form of creatine, the recommended doses of KA $(1.5 \mathrm{~g} / \mathrm{d})$ would be as effective or more effective than consuming standard loading (20 g/d for 7-day) and maintenance doses $(5 \mathrm{~g} / \mathrm{d}$ for 21-days) of CrM on increasing muscle creatine levels and training adaptations with fewer side effects. Additionally, ingesting creatine equivalent loading and maintenance doses of KA would theoretically promote greater effects with fewer side effects in those ingesting standard loading and maintenance doses of CrM.

\section{Methods}

\section{Experimental design}

Table 1 presents the general experimental design employed in this study. The study was conducted in a double-blind, randomized controlled manner. The independent variable was the type of creatine ingested. Dependent variables included muscle creatine content, body composition, one repetition maximum (1RM) bench press and leg press, anaerobic sprint performance capacity, serum and whole blood clinical markers of health, and self-reported side effects. Dietary intake was not controlled but participant's dietary intake was recorded prior to each testing session and analyzed for energy intake and macronutrient content. Participants were instructed to maintain their normal resistancetraining program and maintain training logs so training volume could be compared. Subjects who qualified for the study participated in a familiarization session in which the study was explained to the participants and informed consent was obtained. After the familiarization session, subjects were matched for bodyweight, years of training experience, and age and randomly assigned to one of three groups: 1.) KA at manufacturer's recommended doses (KA-L, $1.5 \mathrm{~g} / \mathrm{d}$ for 28-days); 2.) KA at creatine equivalent loading ( 4 x $5 \mathrm{~g} / \mathrm{d}$ for 7 -days) and maintenance (5 g/d for 21-days) doses as CrM (KA-H); or, 3.) $\mathrm{CrM}$ at normal loading ( $4 \times 5 \mathrm{~g} / \mathrm{d}$ for 7 -days) and maintenance doses (5 g/d for 21-days).

\section{Participants}

Apparently healthy resistance-trained males with no selfreported recent history of creatine supplementation were recruited to participate in this study. Participants were not allowed to participate in this study if they had any metabolic disorder including known electrolyte abnormalities; heart disease, arrhythmias, diabetes, thyroid disease, or hypogonadism; a history of hypertension, hepatorenal, musculoskeletal, autoimmune, or neurologic disease; if they were taking thyroid, anti-hyperlipidemic, hypoglycemic, anti-hypertensive, anti-inflammatory, or androgenic medications; or, if they had taken dietary supplements containing creatine within three months prior to the start of the study. Participants were recruited from the student population and from area fitness facilities. Participants completed demographic, health history and exercise history forms. Those who met eligibility criteria were informed of the requirements of the study and signed informed consent statements in compliance with the Human Subjects Guidelines of Texas A\&M University and the American College of Sports Medicine. Subjects participated in a familiarization session that included practicing the Wingate anaerobic capacity test.

\section{Testing sessions}

Participants were instructed to record all food ingestion on food record forms four days (4-d) prior to the start of the study. In addition, subjects were asked to fast for 8 hours and abstain from exercise for 48 hours prior to baseline testing. Once reporting to the lab, subjects donated a muscle biopsy and fasting blood samples using standard clinical procedures. Subjects were then weighed, had body water assessed using a bioelectrical impedance analyzer (BIA), and body composition assessed using a Dual-Energy X-Ray Absorptiometer (DEXA). They also performed 1RM tests on the bench press and hip sled/leg press and performed a 30-second Wingate anaerobic capacity sprint test on a cycle ergometer. Subjects then began a 7-day initial supplementation phase. After 7 days, subjects repeated all tests with the exception of 1RM strength measures. The subjects then followed supplementation schedules for 21-days and 
Table 1 Overview of Study Design

\begin{tabular}{llll}
\hline Familiarization and Entry & Baseline Day 0 & Loading Phase Day 7 & Maintenance Phase Day 28 \\
\hline Familiarization session & 4-Day Diet History & 4-Day Diet History & 4-Day Diet History \\
Informed Consent Form & Muscle Biopsy & Submit Training Log & Submit Training Log \\
Demographic Form & Fasting Blood Sample & Muscle Biopsy & Muscle Biopsy \\
Body Weight & Body Water (BIA) & Fasting Blood Sample & Fasting Blood Sample \\
Health History Form & DEXA Body Composition & Body Weight & Body Weight \\
$\begin{array}{l}\text { Exercise History Form } \\
\text { 4-day Dietary History }\end{array}$ & 1 RM Leg Press & Body Water (BIA) & Body Water (BIA) \\
$\begin{array}{l}\text { General Exam to Determine } \\
\text { Qualifications to Participate } \\
\text { in Study }\end{array}$ & 1 RM Bench Press & DEXA Body Composition & DEXA Body Composition \\
Height and Body Weight & Wingate Anaerobic & Wingate Anaerobic Capacity Test & 1 RM Leg Press \\
$\begin{array}{l}\text { Practice Wingate Anaerobic } \\
\text { Capacity Test }\end{array}$ & Loading Phase of \\
$\begin{array}{l}\text { Randomization into one of } \\
\text { three groups (CrM, KA-L, KA-H) } \\
\text { Instructions for Supplementation }\end{array}$ & Supplementation Begins & Low-Dose Maintenance Phase & 1 RM Bench Press \\
\hline
\end{tabular}

returned to undergo all tests. This allowed for the assessment of acute and chronic supplementation protocols on muscle creatine levels, body composition, exercise performance, as well as markers of clinical health and safety. Participants were asked to maintain their current training programs and record all workouts. Participants were also asked to report side effects on a weekly basis.

\section{Supplementation protocol}

Participants were matched into one of three groups according to body weight, training status/experience, and age. Subjects were then randomly assigned to one of three groups to ingest, in a double blind manner, capsules containing CrM (Creapure ${ }^{\circledR}$ AlzChem AG, Trostberg, Germany, Lot \#108631) or KA (Kre-Alkalyn ${ }^{\circledR}$ All American Pharmaceutical, Billings, MT, USA, Lot \#1067000) at two different dosages. Supplements were provided by the supporting sponsor in red 0.75 gram (00 sized) capsules and placed in generic single-serving packets that were put in labeled containers for doubleblind administration on a weekly basis. Creatine content of the capsules was independently verified by Covance Laboratories (Madison, WI). Certificate of analysis results are presented in Table 2. Participants in the CrM groups ingested 8 capsules per serving containing approximately $5 \mathrm{~g}$ of CrM four times daily $(20 \mathrm{~g} / \mathrm{d})$ for 7 days and once per day $(5 \mathrm{~g} / \mathrm{d})$ for 21-days. A small amount of dextrose ( $\sim 60 \mathrm{mg}$ per capsule) was added to the CrM capsules to enhance flowability during encapsulation. Participants in the KA creatine monohydrate equivalent group (KA-H) ingested 8 capsules per serving containing approximately $5 \mathrm{~g}$ of $\mathrm{CrM}$ four times daily $(20 \mathrm{~g} / \mathrm{d})$ for 7 -days and once per day $(5 \mathrm{~g} / \mathrm{d})$ for 21 -days. Participants assigned to ingest the manufacturers recommended doses of KA (KA-L) ingested 8 capsules containing a total of approximately $1.5 \mathrm{~g}$ of $\mathrm{KA}$ mixed with $3.5 \mathrm{~g}$ of dextrose once per day and 8 capsules containing $5 \mathrm{~g}$ of dextrose three times per day during the initial 7day loading period. Thereafter, participants in the KA-L group ingested 8 capsules per day containing $1.5 \mathrm{~g} / \mathrm{d}$ of KA mixed with $3.5 \mathrm{~g}$ of dextrose for 21-days. Participants were instructed to ingest supplements at 8:00 am, 12:00 pm, 4:00 pm, and 8:00 pm during the initial 7-day supplementation period and at 8:00 am during the maintenance phase. Supplementation compliance was monitored by having the subjects return empty containers of the supplements at the end of each week. In addition, subject's compliance was verified by administering and collecting weekly questionnaires. After completing the

Table 2 Supplement Certificate of Analysis Results

\begin{tabular}{|c|c|c|c|c|c|c|}
\hline Group & $\begin{array}{l}\text { Entity Weight } \\
(\mathrm{g})\end{array}$ & $\begin{array}{l}\text { Fill Weight } \\
\text { (g) }\end{array}$ & $\begin{array}{c}\text { Moisture } \\
(\%)\end{array}$ & $\begin{array}{c}\text { Creatine Monohydrate } \\
(\%)\end{array}$ & $\begin{array}{l}\text { Total Creatine Monohydrate } \\
\text { (g/per } 8 \text { capsules) }\end{array}$ & $\begin{array}{c}\text { Creatinine } \\
\text { (ppm) }\end{array}$ \\
\hline KA-L & 0.7609 & 0.6375 & 8.2 & 30.6 & 1.56 & $<5,000$ \\
\hline $\mathrm{KA}-\mathrm{H}$ & 0.7566 & 0.6358 & 8.8 & 102.0 & 5.19 & $<5,000$ \\
\hline $\mathrm{CrM}$ & 0.8171 & 0.6975 & 9.4 & 92.4 & 5.16 & $<5,000$ \\
\hline
\end{tabular}

Samples analyzed by Covance Laboratory Inc. (Madison, WI). Sample size was eight capsules. 
compliance procedures, the subjects were given the required supplements for the next week.

\section{Procedures \\ Diet and training analysis}

Participants were instructed to maintain their current dietary habits and to keep detailed dietary records. Prior to each testing session subjects completed a dietary record that included 3 weekdays and 1 weekend day. Dietary inventories were reviewed by a registered dietitian and analyzed for average energy and macronutrient intake using the Food Processor Nutrition Analysis Software Version 9.1.0 (ESHA Nutrition Research, Salem, $O R$ ). Participants were also instructed to maintain their current training regimen and record the type and number of sets and repetitions performed on training logs. Training volume was calculated by multiplying the amount of weight lifted times the number of repetitions performed for each set performed. Total training volume during the study was analyzed by summing all lifts (upper and lower body) to determine if there were any differences among groups.

\section{Body composition}

Body composition testing occurred on day 0, 7 and 28 of the study. Height and weight were recorded to the nearest $0.02 \mathrm{~kg}$ and $0.01 \mathrm{~cm}$, respectively, using a selfcalibrating digital scale (Cardinal Detecto Scale Model 8430, Webb City, Missouri). Body composition was determined using a Hologic Discovery W QDR series DEXA system (Hologic Inc., Waltham, MA) equipped with APEX software (APEX Corporation Software version 12.1, Pittsburgh, $P A$ ). Quality control calibration procedures were performed on a spine phantom (Hologic-XCLAIBER Model DPA/QDR-1 anthropometric spine phantom) and a density step calibration phantom prior to each testing session. DEXA has been validated as an accurate method for body composition assessment [40]. Mean test-retest reliability studies performed on male athletes in our lab has yielded mean coefficients of variation for total bone mineral content and total fat free/ soft tissue mass of $0.31 \%$ to $0.45 \%$ with a mean intraclass correlation of 0.985 [41]. Body water was estimated using an ImpediMed DF50 bioelectrical impedance analyzer (ImpediMed, San Diego, CA).

\section{Blood and muscle samples}

Subjects donated approximately $10 \mathrm{ml}$ of fasting blood using venipuncture techniques from an antecubital vein in the forearm according to standard sterile procedures. Serum blood samples were sent to Quest Diagnostics (Houston, TX) for comprehensive metabolic panel analysis using an Olympus AAU 5400 Chemistry Immuno Analyzer (Olympus America Inc., Center Valley, PA).
Whole blood samples were analyzed for complete blood counts with platelet differentials using an Abbott Cell Dyn 3500 automated hematology analyzer (Abbott Laboratories, Abbott Park, IL). Reported test to test reliability of performing these assays generally range from 2 to $6 \%$ for individual assays. Samples were run in duplicate to verify results if the observed values were outside control values and/or clinical norms according to standard procedures.

Muscle biopsies were obtained using a modified Bergstrom needle biopsy technique following standard procedures [42]. Percutaneous muscle biopsies (50-70 mg) were obtained from the middle portion of the vastus lateralis muscle of the dominant leg at the midpoint between the patella and the greater trochanter of the femur at a depth between 1 and $2 \mathrm{~cm}$ into the muscle. For the remaining two biopsies, attempts were made to extract tissue from approximately the same location as the initial biopsy by using the pre-biopsy scar, depth markings on the needle, and successive incisions that were made approximately $2 \mathrm{~cm}$ proximal to the former site. After removal, adipose tissue was trimmed from the muscle specimens which were then immediately frozen in liquid nitrogen and then stored at $-80^{\circ} \mathrm{C}$ for later analysis. A total of three muscle samples were obtained (Day 0, 7, \& 28). Muscle tissue samples were analyzed spectrophotometrically in duplicate for creatine $(\mathrm{Cr})$ using methods developed by Harris and colleagues [7,8,43]. Briefly, approximately $50-70 \mathrm{mg}$ of muscle tissue was cut and placed in a microfuge tube, and then placed in a vacuum centrifuge (Savant ISS110 SpeedVac Concentrator, Thermo Scientific, Milford, MA) and centrifuged for 1824 hours. Connective tissue was removed from the dried samples which were then grinded into a powder in a porcelain plate and placed into pre-weighed microfuge tubes. Muscle metabolites were extracted in a $0.5 \mathrm{M}$ perchloric acid/ $1 \mathrm{mM}$ EDTA solution on ice for 15 minutes, while periodically vortexing. Samples were then centrifuged at 7,000 rpm for 5 minutes. The supernatant was transferred into a pre-weighed microfuge tube and neutralized with 2.1 M KHCO3/0.3 M MOPS solution. The samples were then centrifuged again at 7,000 rpm for 5 minutes and the supernatant was removed and placed into microfuge tubes and frozen at $-80^{\circ} \mathrm{C}$.

Extracts were assayed for $\mathrm{Cr}$ in the presence of $50 \mathrm{mM}$ imidazole buffer, $\mathrm{pH}$ 4.7; $5 \mathrm{mM}$ magnesium chloride; $20 \mathrm{mM}$ potassium chloride; $25 \mu \mathrm{M}$ phosphoenolpyruvate; $200 \mu \mathrm{M}$ ATP; $45 \mu \mathrm{M}$ NADH; $1250 \mathrm{U} / \mathrm{mL}$ lactate dehydrogenase; $2000 \mathrm{U} / \mathrm{mL}$ pyruvate kinase. The assay was carried out in a standard fluorescence microplate reader using 10 $\mu \mathrm{L}$ of sample to $1 \mathrm{~mL}$ of reagent. The reactant solution was vortexed and read using a fluorometer (Shimadzu RFMini 150, Japan) with an excitation wavelength of $340 \mathrm{~nm}$ and an emission wavelength of $460 \mathrm{~nm}$ for 
baseline absorbance values. Five $\mu \mathrm{L}$ of CK $(25 \mu / \mathrm{mg})$ was added to $1 \mathrm{~mL}$ of the above buffer and stabilized using $1 \mathrm{~mL}$ of reagent. After 10 minutes the plate was read again for post-reaction absorbance values. Test to test reliability of duplicate muscle creatine assays was $0.22 \pm 2.4 \%$ $(r=0.90)$ with a coefficient of variation of 6.8. We also assayed muscle samples for phosphocreatine $(\mathrm{PCr})$ but several values were out of normal ranges, there was large variability in values observed, and overall $\mathrm{PCr}$ levels declined over time despite creatine supplementation suggesting a lack of validity in this assay. Therefore, these data were not reported.

\section{Performance tests}

Maximal strength tests were performed using a standard isotonic Olympic bench press and hip sled/leg press (Nebula Fitness, Versailles, $\mathrm{OH}$ ) according to standardized procedures [44]. Hand positioning on the bench press and foot and seat position on the hip sled/leg press were standardized between trials. Participants followed a standardized warm-up (10 repetitions at $50 \%$ of $1 \mathrm{RM}$ ) prior to beginning $1 \mathrm{RM}$ attempts. Rest recovery was standardized between attempts at 2-min and participants typically reached their $1 R M$ within 3-5 attempts after warming up. Participants performed the hip sled/leg press 1RM test, rested for 4 minutes, and then began warming up on the bench press. Bench press 1RM was determined following similar procedures as the hip sled/ leg press $1 \mathrm{RM}$ test. Test-to-test reliability of performing these tests in our lab on resistance-trained participants have yielded low day to day mean coefficients of variation and high reliability for the bench press $(1.1 \%$, intra-class $r=0.99)$ and hip sled/leg press $(0.7 \%$, intraclass $r=0.91)$. Subjects rested for about 20-minutes and then warmed up on a bicycle ergometer for 3-minutes (70 rpm @ $1 \mathrm{~kg}$ resistance). Participants then performed a 30-second Wingate sprint anaerobic capacity test on a Lode Excalibur Sport 925900 cycle ergometer (Lode BV, Groningen, The Netherlands) at a standardized work rate of $7.5 \mathrm{~J} / \mathrm{kg} / \mathrm{rev}$. The seat position was standardized between trials and the participant was asked to pedal as fast as possible prior to application of the workload and sprint at all-out maximal capacity during the 30 -second test. Test-to-test variability in performing repeated Wingate anaerobic capacity tests in our laboratory yielded correlation coefficients of $r=0.98 \pm 15 \%$ for mean power. Participants practiced the anaerobic capacity test during the familiarization session to minimize learning effects.

\section{Side effect assessment}

Participants were given weekly questionnaires on how well they tolerated the supplement, how well they followed the supplement protocol, and if they experienced any medical problems/symptoms during the study.
Compliance to the supplementation protocol was monitored by turning in empty weekly supplement containers, supplement logs and verbal confirmation. After completing the compliance procedures, subjects were given the required supplements and dosages for the following supplementation period.

\section{Data analysis}

Participant baseline demographic data were analyzed by one-way Analysis of Variance (ANOVA). Study data were analyzed by Multivariate Analysis of Variance (MANOVA) with repeated measures. Overall MANOVA effects were examined using the Wilks' Lamda time and group $\mathrm{x}$ time p-levels as well as MANOVA univariate ANOVA group effects. Greenhouse-Geisser univariate tests of within-subjects time and group $\mathrm{x}$ time effects and between-subjects univariate group effects were reported for each variable analyzed within the MANOVA model. In some instances, repeated measures ANOVA was run on variables not included in a MANOVA design with univariate group, time, and group $\mathrm{x}$ time interaction effects reported. Data were considered statistically significant when the probability of type I error was 0.05 or less and statistical trends were considered when the probability of error ranged between $p>0.05$ to $p<0.10$. If a significant group, treatment and/or interaction alpha level was observed, Tukey's least significant differences (LSD) post-hoc analysis was performed to determine where significance was obtained. A priori power analysis of the design indicated that an $n$-size of 12 per group was sufficiently powered to identify previously reported changes in muscle creatine content and training adaptations in responses to creatine supplementation $(>0.70)$.

\section{Results}

\section{Subject demographics}

Forty-one participants were initially recruited for the study, completed consent forms and participated in the required familiarization session. Of the original 41 participants, 36 completed the 28-day research study. Three participants dropped out due to time constraints, one due to an unrelated illness, and one due to apprehension of the muscle biopsy procedure. None of the participants dropped out of the study due to side effects related to the study protocol. Table 3 shows the baseline demographics for the participants. Overall, participants were $20.2 \pm 2$ years, $181 \pm 7 \mathrm{~cm}, 82.1 \pm 12 \mathrm{~kg}$, and $14.7 \pm 5 \%$ fat with $3.8 \pm 3$ years of resistance training experience. Oneway ANOVA revealed no significant differences among groups in baseline demographic variables.

\section{Compliance, side effects, training, and diet}

Based on compliance records, all participants exhibited $100 \%$ compliance with the supplementation protocol 
Table 3 Participant Demographics

\begin{tabular}{lcccccc}
\hline Group & $\mathbf{N}$ & Age (years) & Height $(\mathbf{c m})$ & Body Weight $(\mathbf{k g})$ & Body Fat (\%) & Training (years) \\
\hline KA-L & 12 & $19.8 \pm 1.8$ & $180.1 \pm 8.4$ & $83.4 \pm 13.6$ & $17.0 \pm 4.9$ & $12.8 \pm 4.1$ \\
KA-H & 12 & $19.5 \pm 1.2$ & $181.0 \pm 6.3$ & $81.2 \pm 8.1$ & $14.2 \pm 4.7$ & $4.0 \pm 2.9$ \\
CrM & 12 & $21.3 \pm 2.8$ & $181.3 \pm 6.4$ & $81.8 \pm 13.8$ & 0.08 & $4.3 \pm 3.4$ \\
p-level & & 0.07 & 0.91 & 0.90 & 0.55 \\
\hline
\end{tabular}

Values are means \pm standard deviations.

Data were analyzed by one-way ANOVA.

without experiencing any side effects throughout the duration of the 28-day supplementation protocol. Table 4 shows the total training volumes for upper and lower body lifts. One-way ANOVA revealed that there were no significant differences among groups in total upper body training volume $(\mathrm{p}=0.89)$ or lower body training volume $(\mathrm{p}=0.55)$. Table 5 presents mean energy intake and macronutrient content for each group. MANOVA revealed no overall significant Wilks' Lambda time $(\mathrm{p}=0.39)$ or group $\mathrm{x}$ time $(\mathrm{p}=0.56)$ interaction effects in absolute energy intake $(\mathrm{kcal} / \mathrm{d})$, protein intake $(\mathrm{g} / \mathrm{d})$, carbohydrate $(\mathrm{g} / \mathrm{d})$ or fat intake $(\mathrm{g} / \mathrm{d})$. MANOVA univariate analysis revealed a significant time effect suggesting that energy and protein intake tended to decrease during the study but no significant interactions were observed among groups. Similar results were observed when assessing energy and macronutrient intake when expressed relative to body mass.

\section{Muscle creatine analysis}

Table 6 presents muscle free creatine content data while Figure 1 shows changes in muscle free content. Sufficient muscle samples were obtained to measure baseline and subsequent creatine on 25 participants. Subjects with missing baseline or day- 28 data were not included in the analysis. Two day-7 missing creatine values were replaced using the last observed value method. A MANOVA was run on muscle creatine expressed in $\mathrm{mmol} / \mathrm{kg} \mathrm{DW}$ and changes from baseline expressed in $\mathrm{mmol} / \mathrm{kg} \mathrm{DW}$ and percent changes from baseline. An overall MANOVA time effect (Wilks' Lamda $\mathrm{p}=0.002$ ) was observed with no significant overall MANOVA group $\mathrm{x}$ time interactions (Wilks' Lambda $\mathrm{p}=0.55$ ). MANOVA univariate analysis revealed significant time effects in muscle free creatine

Table 4 Training Volume

\begin{tabular}{lcc}
\hline Group & Upper Body $(\mathbf{k g})$ & Lower Body $\mathbf{( k g )}$ \\
\hline KA-L & $65,006 \pm 35,543$ & $40,631 \pm 20,641$ \\
KA-H & $74,445 \pm 42,340$ & $32,930 \pm 20,258$ \\
CrM & $69,227 \pm 62,251$ & $32,665 \pm 19,471$ \\
p-level & 0.89 & 0.55 \\
\hline
\end{tabular}

Training logs were obtained on all participants ( $n=36$ or 12 per group). Values are means \pm standard deviations.

Data were analyzed by one-way ANOVA. content expressed in absolute terms $(p=0.03)$, changes from baseline $(p=0.03)$, and percent changes from baseline $(p=0.003)$. No significant groups $x$ time interactions were observed among groups. However, while no overall group differences were observed $(\mathrm{p}=0.14)$, pairwise comparison between the KA-L and CrM groups revealed that changes in muscle creatine tended to be greater in the CrM group (KA-L $-1.1 \pm 4.3, \mathrm{CrM} 11.2 \pm 4.3 \mathrm{mmol} / \mathrm{kg}$ DW, $\mathrm{p}=0.053 \quad[$ mean \pm SEM]; KA-L 2.4 $\pm 8.5, \quad$ CrM $24.6 \pm 8.5 \%, \mathrm{p}=0.078[$ mean \pm SEM] $)$.

\section{Body composition}

Table 7 presents body composition results observed during the study while Figure 2 shows the changes observed over time in fat free mass and percent body fat. Overall MANOVA revealed significant time effects (Wilks' Lambda $\mathrm{p}=0.001$ ) with no significant group $\mathrm{x}$ time interactions observed (Wilks' Lambda $\mathrm{p}=0.90$ ) in body composition variables. Bodyweight increased in all groups over time $(1.0 \pm 1.9,1.42 \pm 2.5 \mathrm{~kg}, \mathrm{p}<0.001)$ with no significant group $\mathrm{x}$ time interaction effects observed among groups after 7 and 28-days, respectively, of supplementation (KA-L $0.7 \pm 0.83,0.9 \pm 1.6$; KA-H $1.7 \pm 2.9$, $2.3 \pm 3.7 ; \mathrm{CrM} 0.6 \pm 1.1,1.1 \pm 1.4 \mathrm{~kg}, \mathrm{p}=0.35$ ). Fat-free mass significantly increased over time for all groups $(0.67 \pm 1.0,0.89 \pm 1.2 \mathrm{~kg}, \mathrm{p}<0.001)$ with no significant group $x$ time interaction effects observed among groups (KA-L $0.42 \pm 1.2,0.37 \pm 1.3$; KA-H $0.96 \pm 0.9,1.2 \pm 1.4$; CrM $0.6 \pm 0.8,1.1 \pm 0.9 \mathrm{~kg}, \mathrm{p}=0.43)$. Body fat percent was not significantly decreased over time for all groups $(-0.28 \pm 1.0,-0.22 \pm 1.4 \%, \mathrm{p}=0.41)$ and no significant group $\mathrm{x}$ time interactions were observed among groups (KA-L $\quad-0.04 \pm 1.3, \quad 0.15 \pm 1.2 ; \quad$ KA-H $\quad-0.28 \pm 0.7$, $-0.31 \pm 1.6$; CrM $-0.53 \pm 0.9,-0.50 \pm 1.4 \%, \mathrm{p}=0.77)$. Total body water expressed as a percentage of bodyweight significantly decreased over time for all groups $(-1.25 \pm 3.7$, $-2.68 \pm 3.4 \%, \mathrm{p}<0.001)$ with no significant group $\mathrm{x}$ time interaction effects observed among groups (KA-L $-0.58 \pm 4.1, \quad-1.95 \pm 4.4 ; \quad \mathrm{KA}-\mathrm{H}-2.25 \pm 2.0, \quad-3.28 \pm 3.1$; $\mathrm{CrM}-0.92 \pm 4.6,-2.82 \pm 2.6 \%, \mathrm{p}=0.71$ ).

\section{Training adaptations}

Table 8 shows upper and lower body 1RM strength data observed for each group while Figure 3 shows the 
Table 5 Dietary Caloric and Macronutrient Intake

\begin{tabular}{|c|c|c|c|c|c|c|}
\hline \multirow[t]{2}{*}{ Variable } & \multirow[t]{2}{*}{ Group } & \multicolumn{3}{|c|}{ Day } & & \multirow[t]{2}{*}{ p-level } \\
\hline & & 0 & 7 & 28 & & \\
\hline \multirow[t]{3}{*}{ Calories (kcal/day) } & $K A-L$ & $2,167 \pm 900$ & $2,202 \pm 653$ & $1,998 \pm 444$ & Group & 0.29 \\
\hline & $\mathrm{KA}-\mathrm{H}$ & $2,506 \pm 645$ & $2,604 \pm 670$ & $2,321 \pm 677$ & Time & 0.08 \\
\hline & $\mathrm{CrM}$ & $2,511 \pm 582$ & $2,372 \pm 735$ & $2,312 \pm 394$ & $G \times T$ & 0.81 \\
\hline \multirow[t]{3}{*}{ Protein (g/d) } & $K A-L$ & $126.3 \pm 76$ & $126.2 \pm 58$ & $112.4 \pm 46$ & Group & 0.65 \\
\hline & $\mathrm{KA}-\mathrm{H}$ & $139.4 \pm 46$ & $143.2 \pm 54$ & $132.5 \pm 60$ & Time & 0.05 \\
\hline & $\mathrm{CrM}$ & $127.8 \pm 28$ & $131.2 \pm 40$ & $114.1 \pm 35$ & $G \times T$ & 0.97 \\
\hline \multirow[t]{3}{*}{ Carbohydrate $(\mathrm{g} / \mathrm{d})$} & $K A-L$ & $219.1 \pm 73$ & $203.9 \pm 79$ & $181.7 \pm 53$ & Group & 0.53 \\
\hline & $\mathrm{KA}-\mathrm{H}$ & $221.9 \pm 74$ & $216.0 \pm 91$ & $206.1 \pm 86$ & Time & 0.40 \\
\hline & $\mathrm{CrM}$ & $231.0 \pm 72$ & $226.1 \pm 93$ & $242.6 \pm 66$ & $G \times T$ & 0.38 \\
\hline \multirow[t]{3}{*}{ Fat $(g / d)$} & $K A-L$ & $78.6 \pm 38$ & $84.7 \pm 27$ & $71.6 \pm 16$ & Group & 0.20 \\
\hline & $\mathrm{KA}-\mathrm{H}$ & $99.2 \pm 40$ & $105.7 \pm 47$ & $94.5 \pm 35$ & Time & 0.19 \\
\hline & CrM & $91.3 \pm 32$ & $81.3 \pm 30$ & $83.0 \pm 20$ & $G \times T$ & 0.47 \\
\hline Calories & $K A-L$ & $26.2 \pm 10.0$ & $26.6 \pm 7.9$ & $24.4 \pm 7.2$ & Group & 0.29 \\
\hline \multirow[t]{2}{*}{$(\mathrm{kcal} / \mathrm{kg} / \mathrm{d})$} & $\mathrm{KA}-\mathrm{H}$ & $31.4 \pm 9.5$ & $32.1 \pm 10.5$ & $28.3 \pm 9.4$ & Time & 0.06 \\
\hline & $\mathrm{CrM}$ & $31.2 \pm 7.5$ & $29.0 \pm 8.8$ & $28.4 \pm 5.8$ & $G \times T$ & 0.73 \\
\hline Protein & $K A-L$ & $1.50 \pm 0.8$ & $1.52 \pm 0.7$ & $1.36 \pm 0.6$ & Group & 0.58 \\
\hline \multirow[t]{2}{*}{$(\mathrm{g} / \mathrm{kg} / \mathrm{d})$} & $\mathrm{KA}-\mathrm{H}$ & $1.75 \pm 0.7$ & $1.76 \pm 0.8$ & $1.61 \pm 0.8$ & Time & 0.04 \\
\hline & $\mathrm{CrM}$ & $1.59 \pm 0.4$ & $1.61 \pm 46$ & $1.41 \pm 0.4$ & $G \times T$ & 0.99 \\
\hline Carbohydrate & KA-L & $2.69 \pm 1.0$ & $2.48 \pm 0.9$ & $2.21 \pm 0.7$ & Group & 0.50 \\
\hline \multirow[t]{2}{*}{$(\mathrm{g} / \mathrm{kg} / \mathrm{d})$} & $\mathrm{KA}-\mathrm{H}$ & $2.75 \pm 0.9$ & $2.65 \pm 1.2$ & $2.46 \pm 1.0$ & Time & 0.24 \\
\hline & CrM & $2.87 \pm 0.9$ & $2.76 \pm 1.1$ & $2.99 \pm 0.9$ & $G \times T$ & 0.34 \\
\hline Fat & $K A-L$ & $0.96 \pm 0.4$ & $1.02 \pm 0.3$ & $0.87 \pm 0.2$ & Group & 0.23 \\
\hline \multirow[t]{2}{*}{$(\mathrm{g} / \mathrm{kg} / \mathrm{d})$} & $\mathrm{KA}-\mathrm{H}$ & $1.24 \pm 0.6$ & $1.31 \pm 0.7$ & $1.16 \pm 0.5$ & Time & 0.14 \\
\hline & $\mathrm{CrM}$ & $1.14 \pm 0.4$ & $1.0 \pm 0.4$ & $1.01 \pm 0.3$ & $G \times T$ & 0.44 \\
\hline
\end{tabular}

Nutritional records were analyzed on all participants ( $n=36$ or 12 per group). Values are means \pm standard deviations. Absolute and relative nutritional data were analyzed by MANOVA. Greenhouse-Geisser time and group x time (G x T) interaction p-levels are reported with univariate group p-levels.

changes in 1RM bench press. There was a significant increase in $1 \mathrm{RM}$ for bench press in all groups over time $(97.6 \pm 22.3$ to $101.3 \pm 22.6 \mathrm{~kg}, \quad \mathrm{p}<0.001)$ with no significant group $\mathrm{x}$ time interactions observed among groups in changes in bench press 1RM (KA-L $3.22 \pm 1.5$, $\mathrm{KA}-\mathrm{H} 3.3 \pm 6.8$, CrM $4.5 \pm 3.7 \mathrm{~kg}, \mathrm{p}=0.73)$. There was

Table 6 Muscle Creatine Levels

\begin{tabular}{|c|c|c|c|c|c|c|c|}
\hline \multirow[t]{2}{*}{ Variable } & \multirow[t]{2}{*}{$\mathrm{N}$} & \multirow[t]{2}{*}{ Group } & \multicolumn{3}{|c|}{ Day } & & \multirow[t]{2}{*}{ p-level } \\
\hline & & & 0 & 7 & 28 & & \\
\hline \multirow[t]{3}{*}{$\overline{\mathrm{Cr}}(\mathrm{mmol} / \mathrm{kg} \mathrm{DW})$} & 8 & KA-L & $65.8 \pm 15.4$ & $57.9 \pm 16.1$ & $70.5 \pm 20.9$ & Group & 0.74 \\
\hline & 9 & $\mathrm{KA}-\mathrm{H}$ & $57.3 \pm 17.7$ & $58.3 \pm 15.6$ & $66.3 \pm 12.6$ & Time & 0.03 \\
\hline & 8 & $\mathrm{CrM}$ & $51.5 \pm 12.7$ & $62.8 \pm 25.0$ & $73.8 \pm 15.6$ & $G \times T$ & 0.46 \\
\hline $\mathrm{Cr}$ & 8 & KA-L & $0.0 \pm 0.0$ & $-8.0 \pm 22.3$ & $4.71 \pm 27.0$ & Group & 0.14 \\
\hline \multirow[t]{2}{*}{$(\Delta \mathrm{mmol} / \mathrm{kg} \mathrm{DW})$} & 9 & $\mathrm{KA}-\mathrm{H}$ & $0.0 \pm 0.0$ & $1.03 \pm 12.8$ & $9.07 \pm 23.2$ & Time & 0.03 \\
\hline & 8 & $\mathrm{CrM}$ & $0.0 \pm 0.0$ & $11.3 \pm 23.9$ & $22.3 \pm 21.0$ & $G \times T$ & 0.46 \\
\hline \multirow[t]{3}{*}{$\operatorname{Cr}(\Delta \%)$} & 8 & $K A-L$ & $0.0 \pm 0.0$ & $-6.4 \pm 37.8$ & $13.7 \pm 42.2$ & Group & 0.20 \\
\hline & 9 & $\mathrm{KA}-\mathrm{H}$ & $0.0 \pm 0.0$ & $6.2 \pm 29.2$ & $27.3 \pm 49.1$ & Time & 0.003 \\
\hline & 8 & $\mathrm{CrM}$ & $0.0 \pm 0.0$ & $23.5 \pm 49.0$ & $50.4 \pm 44.8$ & $G \times T$ & 0.51 \\
\hline
\end{tabular}

Values are means \pm standard deviations. $\Delta$ represents change from baseline values. Sufficient muscle samples were obtained to measure baseline and subsequent $\mathrm{Cr}$ on 25 participants. Missing day-7 data in participants with baseline and day- 28 values were replaced using the last observed value method ( $\mathrm{n}=2$ ). Data were analyzed by MANOVA with repeated measures. Greenhouse-Geisser time and group $x$ time $(G \times T)$ interaction p-levels are reported with univariate group p-levels. 


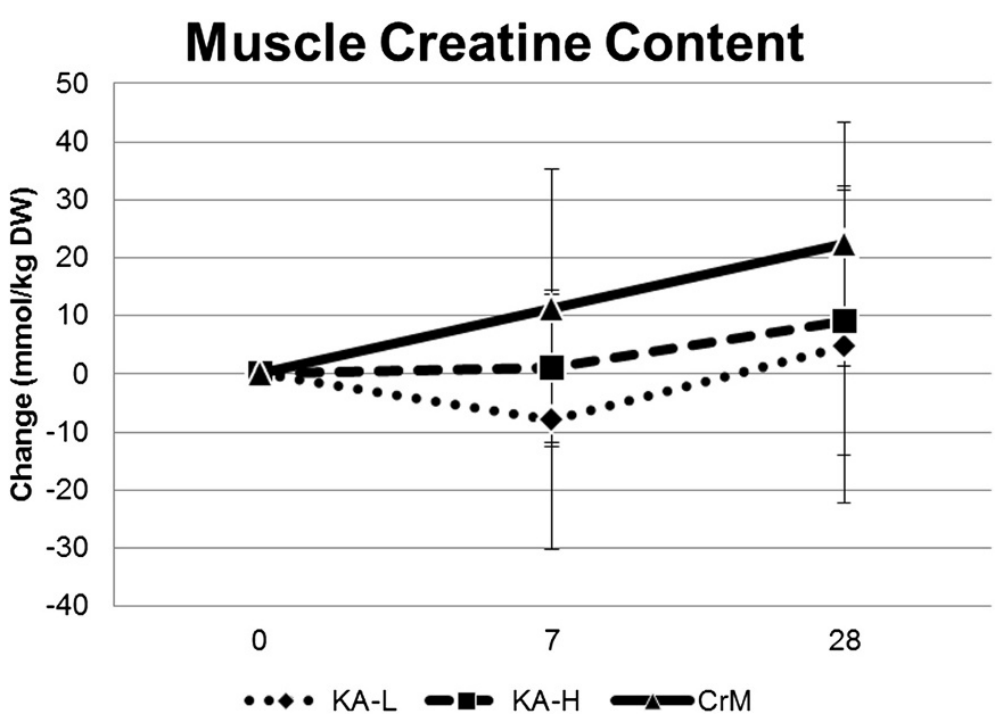

Figure 1 Changes in muscle free creatine content from baseline.

no significant difference observed in hip sled/leg press $1 \mathrm{RM}$ over time $(449.5 \pm 162,471.1 \pm 167, \mathrm{p}=0.33)$ or interactions observed among groups in changes in hip sled/leg press 1RM (KA-L $8.7 \pm 111$, KA-H $68.8 \pm 96$, $\mathrm{CrM}-13.3 \pm 185 \mathrm{~kg}, \mathrm{p}=0.33)$ Table 9 shows results for the anaerobic capacity test while Figure 4 presents changes in total work observed for each group. MANOVA analysis revealed an overall time effect (Wilks' Lambda $\mathrm{p}=0.001$ ) with no significant overall group $\mathrm{x}$ time effects (Wilks' Lambda $\mathrm{p}=0.47$ ) in anaerobic capacity variables. Univariate MANOVA analysis revealed that average power $(p=0.005)$, peak power $(p=0.003)$, and total work $(\mathrm{p}=0.005)$ increased in all groups over time with no significant group $\mathrm{x}$ time interactions observed among groups. Total work performed on the anaerobic capacity sprint test increased in all groups over time $(-69 \pm 1,030,552 \pm 1,361 \mathrm{~J}, \mathrm{p}=0.02)$ with no significant group $\mathrm{x}$ time effects observed among groups

Table 7 Body Composition

\begin{tabular}{|c|c|c|c|c|c|c|}
\hline \multirow[t]{2}{*}{ Marker } & \multirow[t]{2}{*}{ Group } & \multicolumn{3}{|c|}{ Day } & & \multirow[t]{2}{*}{ p-level } \\
\hline & & 0 & 7 & 28 & & \\
\hline \multirow[t]{3}{*}{ Body Weight (kg) } & KA-L & $83.4 \pm 13.6$ & $84.1 \pm 14.0$ & $84.3 \pm 13.6$ & Group & 0.94 \\
\hline & $\mathrm{KA}-\mathrm{H}$ & $81.2 \pm 8.1$ & $83.0 \pm 9.7$ & $83.5 \pm 10.3$ & Time & 0.001 \\
\hline & $\mathrm{CrM}$ & $81.8 \pm 13.8$ & $82.3 \pm 13.6$ & $82.9 \pm 13.0$ & $G \times T$ & 0.35 \\
\hline \multirow[t]{3}{*}{ Fat Mass (kg) } & KA-L & $13.5 \pm 5.4$ & $13.7 \pm 5.9$ & $13.8 \pm 5.8$ & Group & 0.11 \\
\hline & $\mathrm{KA}-\mathrm{H}$ & $9.7 \pm 3.2$ & $9.6 \pm 3.1$ & $9.6 \pm 3.1$ & Time & 0.82 \\
\hline & $\mathrm{CrM}$ & $11.0 \pm 5.3$ & $10.7 \pm 5.4$ & $10.6 \pm 4.4$ & $G \times T$ & 0.73 \\
\hline \multirow[t]{3}{*}{ Fat-Free Mass (kg) } & $K A-L$ & $61.3 \pm 8.7$ & $61.7 \pm 8.6$ & $61.7 \pm 8.8$ & Group & 0.77 \\
\hline & $\mathrm{KA}-\mathrm{H}$ & $63.5 \pm 8.0$ & $64.4 \pm 8.0$ & $64.7 \pm 8.4$ & Time & 0.001 \\
\hline & $\mathrm{CrM}$ & $62.3 \pm 9.8$ & $63.0 \pm 9.6$ & $63.4 \pm 9.9$ & $G \times T$ & 0.43 \\
\hline \multirow[t]{3}{*}{ Body Fat Percent (\%) } & $K A-L$ & $17.0 \pm 4.9$ & $17.0 \pm 5.5$ & $17.2 \pm 5.4$ & Group & 0.06 \\
\hline & $\mathrm{KA}-\mathrm{H}$ & $12.8 \pm 4.1$ & $12.5 \pm 3.8$ & $12.5 \pm 3.6$ & Time & 0.41 \\
\hline & $\mathrm{CrM}$ & $14.2 \pm 4.7$ & $13.7 \pm 5.0$ & $13.7 \pm 4.2$ & $G \times T$ & 0.77 \\
\hline \multirow[t]{3}{*}{ Total Body Water (\%) } & $K A-L$ & $37.8 \pm 5.0$ & $37.2 \pm 4.4$ & $35.9 \pm 3.3$ & Group & 0.26 \\
\hline & $\mathrm{KA}-\mathrm{H}$ & $37.4 \pm 2.9$ & $35.1 \pm 2.6$ & $34.1 \pm 1.7$ & Time & 0.00 \\
\hline & $\mathrm{CrM}$ & $36.7 \pm 2.7$ & $35.8 \pm 3.0$ & $33.9 \pm 1.5$ & $G \times T$ & 0.71 \\
\hline
\end{tabular}

Values are means \pm standard deviations. DEXA body composition and BIA determined body water were determined on 36 participants (12 per group). Body composition variables were analyzed by MANOVA with repeated measures. Greenhouse-Geisser time and group $x$ time ( $\mathrm{x} T$ ) interaction $p$-levels are reported with univariate group p-levels. 

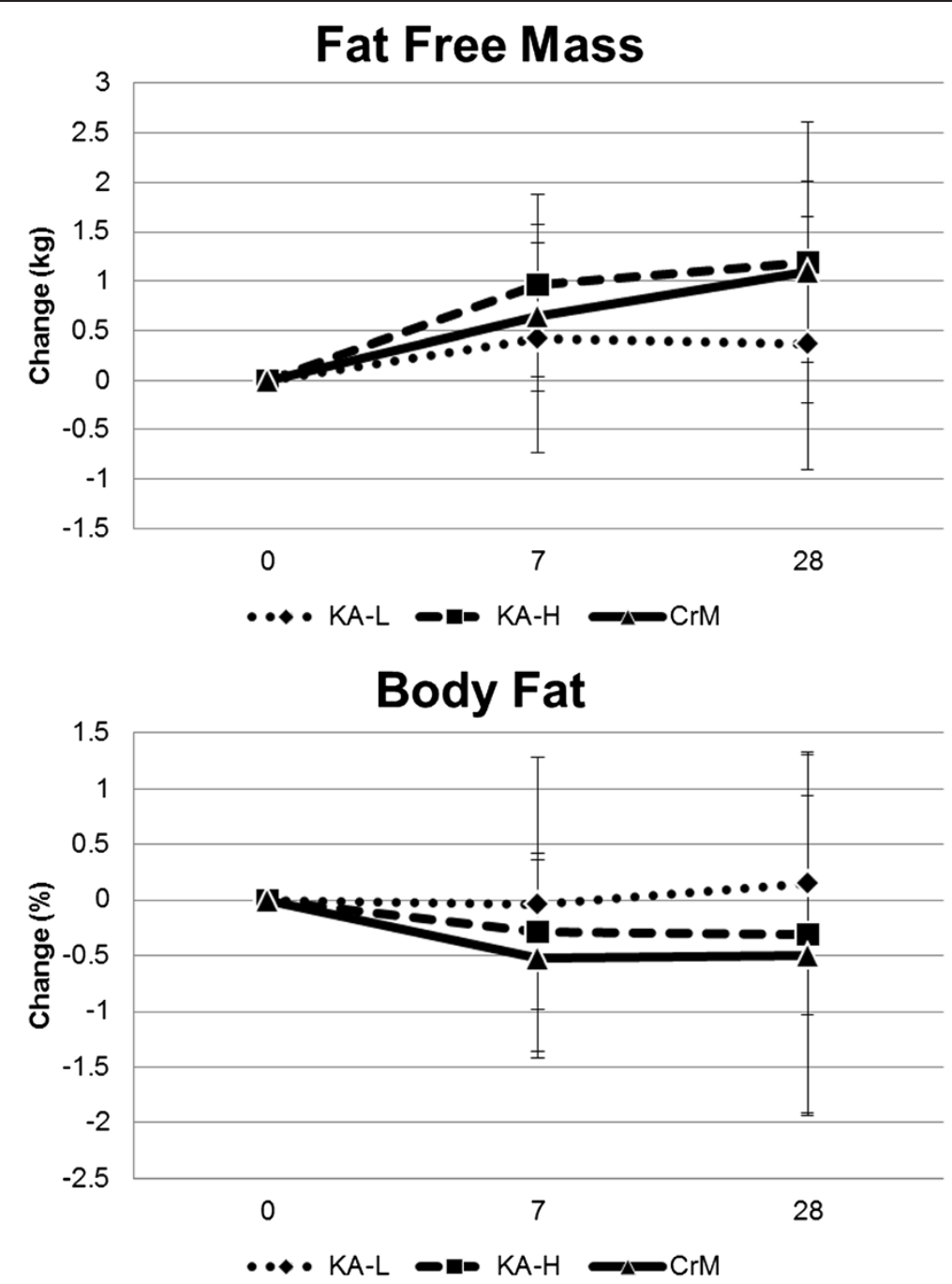

Figure 2 Changes in fat free mass and body fat from baseline.

(KA-L $-278 \pm 676, \quad 64 \pm 1,216 ; \quad K A-H \quad 412 \pm 1,041, \quad$ Lambda $\mathrm{p}=0.17$ ) or groups $\mathrm{x}$ time effects (Wilks' $842 \pm 1,369 ; \mathrm{CrM}-301 \pm 1,224,775 \pm 1,463 \mathrm{~J}, \mathrm{p}=0.32$ ). $\quad$ Lambda 0.15$)$ in blood lipids. Univariate MANOVA also

\section{Clinical chemistry panels}

Table 10 presents blood lipid data observed throughout the study Overall MANOVA revealed no time (Wilks' found no group $\mathrm{x}$ time interactions in total cholesterol (TCHL, $\mathrm{p}=0.10)$, high-density lipoprotein (HDL, $\mathrm{p}=0.64)$, the ratio of TCHL to HDL $(\mathrm{p}=0.09)$, and triglycerides (TRIG, $\mathrm{p}=0.45$ ). Some group $\mathrm{x}$ time effects

Table 8 One Repetition Maximum Strength

\begin{tabular}{|c|c|c|c|c|c|c|}
\hline \multirow[t]{2}{*}{ Variable } & \multirow[t]{2}{*}{$\mathbf{N}$} & \multirow[t]{2}{*}{ Group } & \multicolumn{2}{|c|}{ Day } & & \multirow[t]{2}{*}{ p-level } \\
\hline & & & 0 & 28 & & \\
\hline \multirow[t]{3}{*}{ Upper Body (kg) } & 12 & $K A-L$ & $95.3 \pm 25.4$ & $98.6 \pm 24.7$ & Group & 0.89 \\
\hline & 11 & $\mathrm{KA}-\mathrm{H}$ & $98.4 \pm 18.2$ & $101.7 \pm 17.3$ & Time & 0.001 \\
\hline & 12 & $\mathrm{CrM}$ & $99.12 \pm 24.0$ & $103.7 \pm 26.1$ & $\mathrm{G} \times \mathrm{T}$ & 0.73 \\
\hline \multirow[t]{3}{*}{ Lower Body (kg) } & 12 & $K A-L$ & $445.3 \pm 182$ & $454.1 \pm 155$ & Group & 0.52 \\
\hline & 12 & $\mathrm{KA}-\mathrm{H}$ & $465.4 \pm 117$ & $539.0 \pm 163$ & Time & 0.35 \\
\hline & 12 & $\mathrm{CrM}$ & $439.1 \pm 189$ & $425.8 \pm 175$ & $G \times T$ & 0.31 \\
\hline
\end{tabular}

Values are means \pm standard deviations. Data were analyzed by MANOVA with repeated measures. Greenhouse-Geisser time and group $x$ time ( $\mathrm{x} T$ ) interaction p-levels are reported with univariate group p-levels. 


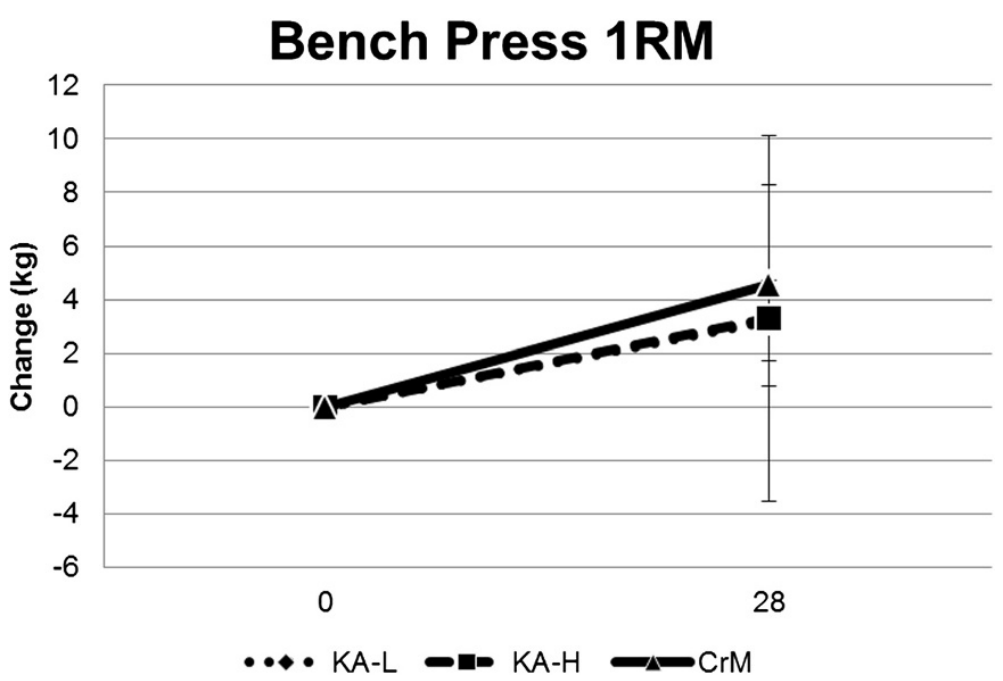

Figure 3 Changes in bench press 1 RM strength from baseline.

were observed among groups in low-density lipoprotein (LDL) levels $(\mathrm{p}=0.005)$ with LDL levels significantly decreasing after the loading phase in the CrM group. However, values remained low and near baseline. Univariate ANOVA revealed no significant differences among groups in blood glucose $(\mathrm{p}=0.67)$.

Table 11 shows markers of catabolism and bone status. Overall MANOVA revealed significant time (Wilks' Lambda $\mathrm{p}<0.001$ ) effects with no significant group $\mathrm{x}$ time effects (Wilks' Lambda $\mathrm{p}=0.19$ ) in markers of catabolism. Univariate MANOVA found no significant group $\mathrm{x}$ time interactions in blood urea nitrogen (BUN, $\mathrm{p}=0.75), \mathrm{BUN}$ to creatinine ratio $(\mathrm{p}=0.24)$, aspartate aminotransferase (AST, $\mathrm{p}=0.68$ ), alanine aminotransferase (ALT, $\mathrm{p}=0.48$ ), total protein $(\mathrm{p}=0.84)$, and total bilirubin (TBIL, $\mathrm{p}=0.26)$. Serum creatinine levels increased in all groups $(\mathrm{p}<0.001)$ over time with a significant group $x$ time interaction demonstrating higher doses of creatine in the $\mathrm{CrM}$ and $\mathrm{KA}-\mathrm{H}$ groups promoting significantly greater increases in serum creatinine $(\mathrm{p}=0.03)$ than the KA-L group. However, creatinine levels in the $\mathrm{CrM}$ and $\mathrm{KA}-\mathrm{H}$ groups were only 0.1 $-0.2 \mathrm{mg} / \mathrm{dL}$ greater than the KA-L group, well within normal values for active individuals, and of no clinical significance. MANOVA analysis of bone related markers found no significant time (Wilks' Lambda $\mathrm{p}=0.83$ ) or group $\mathrm{x}$ time effects (Wilks' Lambda $\mathrm{p}=0.78$ ). Likewise, univariate MANOVA analysis revealed no significant interactions among groups in bone mineral content $(\mathrm{p}=0.66)$, albumin (ALB, $\mathrm{p}=0.89$ ), globulin (GLOB, $p=0.42)$, the ratio of ALB to GLOB $(p=0.45)$, calcium $(\mathrm{p}=0.76)$, or alkaline phosphatase (ALK, $\mathrm{p}=0.65)$.

Table 12 presents serum electrolyte data. Overall MANOVA analysis revealed a significant time effect (Wilks' Lambda $\mathrm{p}=0.02$ ) with no significant overall interaction (Wilks' Lambda $\mathrm{p}=0.26$ ). Univariate MANOVA analysis revealed some small time effects in chloride levels

Table 9 Wingate Anaerobic Sprint Capacity

\begin{tabular}{|c|c|c|c|c|c|c|c|}
\hline \multirow[t]{2}{*}{ Variable } & \multirow[t]{2}{*}{$N$} & \multirow[t]{2}{*}{ Group } & \multicolumn{3}{|c|}{ Day } & & \multirow[t]{2}{*}{ p-level } \\
\hline & & & 0 & 7 & 28 & & \\
\hline \multirow[t]{3}{*}{ Mean Power $(\mathrm{W})$} & 12 & KA-L & $658 \pm 136$ & $651 \pm 134$ & $660 \pm 138$ & Group & 0.61 \\
\hline & 11 & $\mathrm{KA}-\mathrm{H}$ & $689 \pm 99$ & $703 \pm 113$ & $717 \pm 114$ & Time & 0.005 \\
\hline & 12 & $\mathrm{CrM}$ & $660 \pm 119$ & $652 \pm 108$ & $688 \pm 105$ & $G \times T$ & 0.21 \\
\hline \multirow[t]{3}{*}{ Peak Power $(W)$} & 12 & $K A-L$ & $1,274 \pm 259$ & $1,393 \pm 286$ & $1,585 \pm 526$ & Group & 0.50 \\
\hline & 11 & $\mathrm{KA}-\mathrm{H}$ & $1,329 \pm 285$ & $1,538 \pm 389$ & $1,616 \pm 378$ & Time & 0.003 \\
\hline & 12 & $\mathrm{CrM}$ & $1,478 \pm 376$ & $1,626 \pm 281$ & $1,571 \pm 409$ & $G \times T$ & 0.48 \\
\hline \multirow[t]{3}{*}{ Total Work $(J)$} & 12 & $K A-L$ & $19,728 \pm 4,076$ & $19,450 \pm 3,910$ & $19,792 \pm 4,153$ & Group & 0.59 \\
\hline & 11 & $\mathrm{KA}-\mathrm{H}$ & $20,681 \pm 2,968$ & $21,093 \pm 3,387$ & $21,523 \pm 3,432$ & Time & 0.005 \\
\hline & 12 & $\mathrm{CrM}$ & $19,799 \pm 3,564$ & $19,497 \pm 3,210$ & $20,573 \pm 3,128$ & $G \times T$ & 0.22 \\
\hline
\end{tabular}




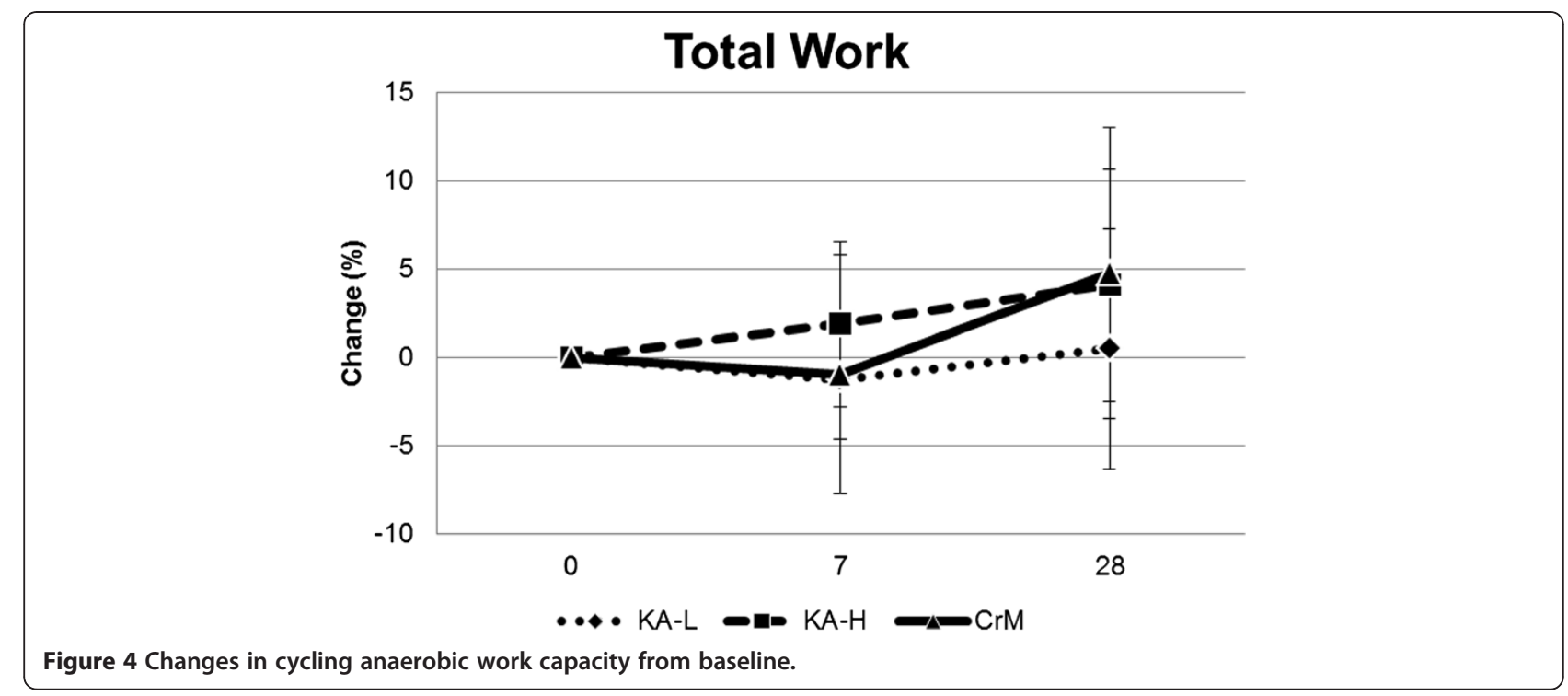

$(\mathrm{p}=0.008)$ and a trend toward an interaction in potassium levels $(p=0.08)$ but the small changes observed would have no clinical significance. Finally, Table 12 shows whole blood markers assessed throughout the study. Overall MANOVA revealed no significant time (Wilks' Lambda $\mathrm{p}=0.25$ ) or group $\mathrm{x}$ time effects (Wilks' Lambda $\mathrm{p}=0.78$ ). Likewise, no significant interactions were observed among groups in white blood cell count (WBC, $\mathrm{p}=0.45)$, red blood cell count (RBC, $\mathrm{p}=0.64)$, hematocrit $(\mathrm{p}=0.65)$, hemoglobin $(\mathrm{p}=0.59)$, mean corpuscular volume $(\mathrm{MCV}$, $\mathrm{p}=0.56)$, mean corpuscular hemoglobin $(\mathrm{MCH}, \mathrm{p}=0.44)$, mean corpuscular hemoglobin concentration ( $\mathrm{MCHC}$, $\mathrm{p}=0.68)$, red blood cell distribution width (RBCDW, $\mathrm{p}=0.92)$, or platelet count $(\mathrm{p}=0.48)$.

Table 10 Serum lipids and glucose

\begin{tabular}{|c|c|c|c|c|c|c|c|}
\hline \multirow[t]{2}{*}{ Marker } & \multirow[t]{2}{*}{$\mathrm{N}$} & \multirow[t]{2}{*}{ Group } & \multicolumn{3}{|c|}{ Day } & & \multirow[t]{2}{*}{ p-leve } \\
\hline & & & 0 & 7 & 28 & & \\
\hline \multirow[t]{3}{*}{ TCHL (mg/dl) } & 11 & KA-L & $149.1 \pm 25$ & $153.0 \pm 23$ & $149.9 \pm 28$ & Group & 0.91 \\
\hline & 12 & $\mathrm{KA}-\mathrm{H}$ & $153.3 \pm 26$ & $152.3 \pm 28$ & $157.5 \pm 22$ & Time & 0.15 \\
\hline & 12 & $\mathrm{CrM}$ & $156.3 \pm 20$ & $147.3 \pm 19$ & $158.9 \pm 21$ & $G \times T$ & 0.10 \\
\hline \multirow[t]{3}{*}{ HDL (mg/dl) } & 11 & KA-L & $48.8 \pm 11.3$ & $51.0 \pm 9.3$ & $52.9 \pm 11.4$ & Group & 0.42 \\
\hline & 12 & $\mathrm{KA}-\mathrm{H}$ & $53.0 \pm 16.0$ & $53.9 \pm 18.4$ & $53.6 \pm 14.4$ & Time & 0.03 \\
\hline & 12 & $\mathrm{CrM}$ & $45.6 \pm 6.5$ & $47.6 \pm 7.3$ & $48.5 \pm 8.4$ & $G \times T$ & 0.64 \\
\hline \multirow[t]{3}{*}{ TCHL: HDL Ratio } & 11 & KA-L & $3.16 \pm 0.7$ & $3.09 \pm 0.6$ & $2.92 \pm 0.7$ & Group & 0.34 \\
\hline & 12 & $\mathrm{KA}-\mathrm{H}$ & $3.03 \pm 0.6$ & $2.95 \pm 0.5$ & $3.04 \pm 0.5$ & Time & 0.04 \\
\hline & 12 & $\mathrm{CrM}$ & $3.48 \pm 0.6$ & $3.15 \pm 0.6$ & $3.36 \pm 0.7$ & $G \times T$ & 0.09 \\
\hline LDL & 11 & KA-L & $83.4 \pm 16^{*}$ & $86.5 \pm 16$ & $81.4 \pm 18^{*}$ & Group & 0.66 \\
\hline \multirow[t]{2}{*}{$(\mathrm{mg} / \mathrm{dl})$} & 12 & $\mathrm{KA}-\mathrm{H}$ & $79.4 \pm 18^{*}$ & $82.7 \pm 19$ & $83.7 \pm 16^{*}$ & Time & 0.42 \\
\hline & 12 & $\mathrm{CrM}$ & $89.8 \pm 20$ & $81.4 \pm 15 \dagger$ & $92.5 \pm 17$ & $G \times T$ & 0.005 \\
\hline \multirow[t]{3}{*}{ TRIG (mg/dl) } & 11 & KA-L & $84.5 \pm 33$ & $77.3 \pm 30$ & $78.5 \pm 37$ & Group & 0.20 \\
\hline & 12 & $\mathrm{KA}-\mathrm{H}$ & $105.1 \pm 37$ & $78.4 \pm 26$ & $101.1 \pm 27$ & Time & 0.07 \\
\hline & 12 & $\mathrm{CrM}$ & $104.1 \pm 28$ & $92.1 \pm 30$ & $89.6 \pm 30$ & $G \times T$ & 0.45 \\
\hline \multirow[t]{3}{*}{ Glucose (mg/dl) } & 11 & KA-L & $93.0 \pm 5.1$ & $90.5 \pm 8.2$ & $93.6 \pm 4.7$ & Group & 0.44 \\
\hline & 12 & $\mathrm{KA}-\mathrm{H}$ & $91.1 \pm 6.6$ & $92.7 \pm 8.1$ & $90.4 \pm 6.9$ & Time & 0.57 \\
\hline & 12 & $\mathrm{CrM}$ & $90.5 \pm 9.6$ & $89.6 \pm 5.5$ & $88.3 \pm 6.3$ & $G \times T$ & 0.67 \\
\hline
\end{tabular}

Values are means \pm standard deviations. Lipid data were analyzed by MANOVA with repeated measures. Greenhouse-Geisser time and group $x$ time ( $\mathrm{x} T$ ) interaction p-levels are reported with univariate group p-levels. Glucose data were analyzed by repeated measures univariate ANOVA. $\dagger$ represents $p<0.05$ difference from baseline. ${ }^{*}$ represents $p<0.05$ difference from $\mathrm{CrM}$. 
Table 11 Markers of catabolism and bone status

\begin{tabular}{|c|c|c|c|c|c|c|c|}
\hline \multirow[t]{2}{*}{ Marker } & \multirow[t]{2}{*}{$\mathrm{N}$} & \multirow[t]{2}{*}{ Group } & \multicolumn{3}{|c|}{ Day } & & \multirow[t]{2}{*}{ p-leve } \\
\hline & & & 0 & 7 & 28 & & \\
\hline \multirow[t]{3}{*}{ BUN (mg/dl) } & 11 & $K A-L$ & $16.0 \pm 5.3$ & $15.3 \pm 4.9$ & $15.6 \pm 5.1$ & Group & 0.89 \\
\hline & 12 & $\mathrm{KA}-\mathrm{H}$ & $16.1 \pm 3.3$ & $16.6 \pm 3.9$ & $16.6 \pm 3.6$ & Time & 0.70 \\
\hline & 12 & $\mathrm{CrM}$ & $16.4 \pm 3.2$ & $15.7 \pm 2.7$ & $16.1 \pm 4.7$ & $G \times T$ & 0.75 \\
\hline Creatinine & 11 & $K A-L$ & $1.04 \pm 0.08$ & $1.08 \pm 0.11$ & $1.13 \pm 0.10 \dagger$ & Group & 0.07 \\
\hline \multirow[t]{2}{*}{$(\mathrm{mg} / \mathrm{dl})$} & 12 & $\mathrm{KA}-\mathrm{H}$ & $1.07 \pm 0.14$ & $1.23 \pm 0.18 t^{*}$ & $1.26 \pm 0.13 t^{*}$ & Time & 0.001 \\
\hline & 12 & $\mathrm{CrM}$ & $1.11 \pm 0.19$ & $1.28 \pm 0.20 十^{*}$ & $1.23 \pm 0.15 t^{*}$ & $G \times T$ & 0.03 \\
\hline \multirow[t]{3}{*}{ BUN:CRN Ratio } & 11 & $K A-L$ & $15.5 \pm 5.1$ & $14.5 \pm 5.6$ & $14.1 \pm 5.6$ & Group & 0.83 \\
\hline & 12 & $\mathrm{KA}-\mathrm{H}$ & $15.1 \pm 3.4$ & $13.7 \pm 3.4$ & $13.3 \pm 3.4$ & Time & 0.001 \\
\hline & 12 & $\mathrm{CrM}$ & $15.2 \pm 3.7$ & $12.4 \pm 2.6$ & $13.2 \pm 3.8$ & $G \times T$ & 0.24 \\
\hline \multirow[t]{3}{*}{ AST $(U / L)$} & 11 & $K A-L$ & $25.4 \pm 9.6$ & $26.5 \pm 8.4$ & $29.5 \pm 12.9$ & Group & 0.62 \\
\hline & 12 & $\mathrm{KA}-\mathrm{H}$ & $27.3 \pm 10.5$ & $25.6 \pm 8.3$ & $32.0 \pm 12.0$ & Time & 0.02 \\
\hline & 12 & $\mathrm{CrM}$ & $24.9 \pm 7.9$ & $23.8 \pm 7.5$ & $26.3 \pm 7.8$ & $G \times T$ & 0.70 \\
\hline \multirow[t]{3}{*}{ ALT $(U / L)$} & 11 & $K A-L$ & $21.5 \pm 11.2$ & $23.5 \pm 14.2$ & $28.7 \pm 19.4$ & Group & 0.50 \\
\hline & 12 & $\mathrm{KA}-\mathrm{H}$ & $24.1 \pm 15.6$ & $22.3 \pm 12.2$ & $27.3 \pm 9.1$ & Time & 0.05 \\
\hline & 12 & $\mathrm{CrM}$ & $21.3 \pm 7.34$ & $18.0 \pm 4.2$ & $21.3 \pm 5.5$ & $G \times T$ & 0.48 \\
\hline \multirow[t]{3}{*}{ Total Protein $(\mathrm{g} / \mathrm{dl})$} & 11 & $K A-L$ & $7.4 \pm 0.6$ & $7.4 \pm 0.4$ & $7.4 \pm 0.4$ & Group & 0.87 \\
\hline & 12 & $\mathrm{KA}-\mathrm{H}$ & $7.3 \pm 0.3$ & $7.3 \pm 0.3$ & $7.3 \pm 0.2$ & Time & 0.88 \\
\hline & 12 & $\mathrm{CrM}$ & $7.3 \pm 0.2$ & $7.3 \pm 0.2$ & $7.4 \pm 0.3$ & $G \times T$ & 0.84 \\
\hline \multirow[t]{3}{*}{ TBIL (mg/dl) } & 11 & $K A-L$ & $0.84 \pm 0.7$ & $0.75 \pm 0.3$ & $0.76 \pm 0.3$ & Group & 0.60 \\
\hline & 12 & $\mathrm{KA}-\mathrm{H}$ & $0.88 \pm 0.5$ & $0.89 \pm 0.5$ & $0.77 \pm 0.4$ & Time & 0.90 \\
\hline & 12 & $\mathrm{CrM}$ & $0.63 \pm 0.2$ & $0.71 \pm 0.2$ & $0.77 \pm 0.2$ & $G \times T$ & 0.26 \\
\hline Bone Mineral & 11 & $K A-L$ & $2,517 \pm 404$ & $2,503 \pm 409$ & $2,505 \pm 398$ & Group & 0.59 \\
\hline \multirow[t]{2}{*}{ Content (g) } & 12 & $\mathrm{KA}-\mathrm{H}$ & $2,632 \pm 457$ & $2,604 \pm 466$ & $2,615 \pm 456$ & Time & 0.49 \\
\hline & 12 & $\mathrm{CrM}$ & $2,446 \pm 344$ & $2,456 \pm 0.2$ & $2,441 \pm 351$ & $G \times T$ & 0.66 \\
\hline \multirow[t]{3}{*}{ Albumin $(\mathrm{g} / \mathrm{dl})$} & 11 & $K A-L$ & $4.80 \pm 0.3$ & $4.81 \pm 0.4$ & $4.81 \pm 0.2$ & Group & 0.95 \\
\hline & 12 & $\mathrm{KA}-\mathrm{H}$ & $4.83 \pm 0.2$ & $4.74 \pm 0.2$ & $4.78 \pm 0.1$ & Time & 0.73 \\
\hline & 12 & $\mathrm{CrM}$ & $4.82 \pm 0.2$ & $4.80 \pm 364$ & $4.79 \pm 0.2$ & $G \times T$ & 0.89 \\
\hline \multirow[t]{3}{*}{ Globulin (g/dl) } & 11 & $K A-L$ & $2.60 \pm 0.4$ & $2.63 \pm 0.3$ & $2.55 \pm 0.3$ & Group & 0.90 \\
\hline & 12 & $\mathrm{KA}-\mathrm{H}$ & $2.56 \pm 0.3$ & $2.58 \pm 0.2$ & $2.52 \pm 0.3$ & Time & 0.85 \\
\hline & 12 & $\mathrm{CrM}$ & $2.55 \pm 0.3$ & $2.54 \pm 0.2$ & $2.62 \pm 0.3$ & $G \times T$ & 0.42 \\
\hline \multirow[t]{3}{*}{ Alb:Glob Ratio } & 11 & $K A-L$ & $1.88 \pm 0.3$ & $1.85 \pm 0.2$ & $1.90 \pm 0.2$ & Group & 0.98 \\
\hline & 12 & $\mathrm{KA}-\mathrm{H}$ & $1.90 \pm 0.1$ & $1.86 \pm 0.2$ & $1.91 \pm 0.1$ & Time & 0.70 \\
\hline & 12 & $\mathrm{CrM}$ & $1.88 \pm 0.2$ & $1.90 \pm 0.2$ & $1.84 \pm 0.2$ & $G \times T$ & 0.45 \\
\hline \multirow[t]{3}{*}{ Calcium (mg/dl) } & 11 & $K A-L$ & $9.87 \pm 0.5$ & $9.85 \pm 0.5$ & $9.76 \pm 0.4$ & Group & 0.42 \\
\hline & 12 & $\mathrm{KA}-\mathrm{H}$ & $9.83 \pm 0.2$ & $9.81 \pm 0.4$ & $9.84 \pm 0.2$ & Time & 0.51 \\
\hline & 12 & $\mathrm{CrM}$ & $9.77 \pm 0.3$ & $9.63 \pm 0.4$ & $9.67 \pm 0.3$ & $G \times T$ & 0.76 \\
\hline \multirow[t]{3}{*}{ ALK $(U / L)$} & 11 & $K A-L$ & $82.0 \pm 16.4$ & $84.1 \pm 20.5$ & $83.9 \pm 17.0$ & Group & 0.88 \\
\hline & 12 & $\mathrm{KA}-\mathrm{H}$ & $81.1 \pm 29.7$ & $83.8 \pm 30.3$ & $87.1 \pm 27.6$ & Time & 0.29 \\
\hline & 12 & $\mathrm{CrM}$ & $78.9 \pm 20.7$ & $80.6 \pm 26.4$ & $78.8 \pm 23.1$ & $G \times T$ & 0.65 \\
\hline
\end{tabular}

Values are means \pm standard deviations. Data were analyzed by MANOVA with repeated measures. Greenhouse-Geisser time and group $\times$ time $(\mathrm{G} \times \mathrm{T})$ interaction $p$-levels are reported with univariate group $p$-levels. $\dagger$ represents $p<0.05$ difference from baseline. * represents $p<0.05$ difference from KA-L.

\section{Discussion}

The purpose of this study was to determine if supplementing the diet with recommended $(1.5 \mathrm{~g} / \mathrm{d}$ for 28 - days) or creatine equivalent loading and maintenance doses of a purported buffered form of creatine $(20 \mathrm{~g} / \mathrm{d}$ for 7 -days and $5 \mathrm{~g} / \mathrm{d}$ for 21 -days) was more effective in 
Table 12 Serum electrolyte status

\begin{tabular}{|c|c|c|c|c|c|c|c|}
\hline \multirow[t]{2}{*}{ Marker } & \multirow[t]{2}{*}{$\mathrm{N}$} & \multirow[t]{2}{*}{ Group } & \multicolumn{3}{|c|}{ Day } & & \multirow[t]{2}{*}{ p-level } \\
\hline & & & 0 & 7 & 28 & & \\
\hline \multirow[t]{3}{*}{ Sodium (mmol/L) } & 11 & KA-L & $140.1 \pm 2.3$ & $139.9 \pm 1.1$ & $140.0 \pm 1.3$ & Group & 0.98 \\
\hline & 12 & $\mathrm{KA}-\mathrm{H}$ & $139.9 \pm 2.3$ & $139.7 \pm 2.4$ & $140.3 \pm 2.1$ & Time & 0.28 \\
\hline & 12 & $\mathrm{CrM}$ & $140.8 \pm 2.1$ & $139.3 \pm 1.4$ & $139.7 \pm 1.6$ & $G \times T$ & 0.57 \\
\hline \multirow[t]{3}{*}{ Potassium (mmol/L) } & 11 & $K A-L$ & $4.54 \pm 0.3$ & $4.86 \pm 0.4$ & $4.82 \pm 0.3$ & Group & 0.65 \\
\hline & 12 & $\mathrm{KA}-\mathrm{H}$ & $4.89 \pm 0.5$ & $4.71 \pm 0.6$ & $5.00 \pm 0.3$ & Time & 0.11 \\
\hline & 12 & $\mathrm{CrM}$ & $4.74 \pm 0.4$ & $4.93 \pm 0.4$ & $4.81 \pm 0.4$ & $G \times T$ & 0.08 \\
\hline \multirow[t]{3}{*}{ Chloride (mmol/L) } & 11 & $K A-L$ & $103.3 \pm 2.2$ & $103.0 \pm 2.4$ & $103.8 \pm 1.9$ & Group & 0.21 \\
\hline & 12 & $\mathrm{KA}-\mathrm{H}$ & $102.4 \pm 2.2$ & $101.5 \pm 2.2$ & $102.6 \pm 2.4$ & Time & 0.008 \\
\hline & 12 & $\mathrm{CrM}$ & $104.3 \pm 2.2$ & $102.3 \pm 1.7$ & $103.1 \pm 1.8$ & $G \times T$ & 0.21 \\
\hline
\end{tabular}

Values are means \pm standard deviations. Data were analyzed by MANOVA with repeated measures. Greenhouse-Geisser time and group $\mathrm{x}$ time $(\mathrm{G} \times \mathrm{T})$ interaction p-levels are reported with univariate group p-levels.

Table 13 Whole blood markers

\begin{tabular}{|c|c|c|c|c|c|c|c|}
\hline \multirow[t]{2}{*}{ Marker } & \multirow[t]{2}{*}{$\mathrm{N}$} & \multirow[t]{2}{*}{ Group } & \multicolumn{3}{|c|}{ Day } & & \multirow[t]{2}{*}{ p-level } \\
\hline & & & 0 & 7 & 28 & & \\
\hline \multirow[t]{3}{*}{$\overline{\text { WBC }\left(\times 10^{3} / \mathrm{ul}\right)}$} & 9 & KA-L & $5.73 \pm 0.6$ & $6.13 \pm 0.5$ & $6.17 \pm 1.5$ & Group & 0.95 \\
\hline & 12 & $\mathrm{KA}-\mathrm{H}$ & $5.83 \pm 1.1$ & $5.76 \pm 0.9$ & $6.36 \pm 1.1$ & Time & 0.16 \\
\hline & 12 & $\mathrm{CrM}$ & $5.97 \pm 1.2$ & $5.73 \pm 1.0$ & $5.98 \pm 1.2$ & $G \times T$ & 0.45 \\
\hline \multirow[t]{3}{*}{ RBC $\left(\times 10^{6} / \mathrm{ul}\right)$} & 9 & KA-L & $5.44 \pm 0.4$ & $5.38 \pm 0.5$ & $5.44 \pm 0.3$ & Group & 0.28 \\
\hline & 12 & $\mathrm{KA}-\mathrm{H}$ & $5.10 \pm 0.4$ & $5.18 \pm 0.3$ & $5.23 \pm 0.3$ & Time & 0.91 \\
\hline & 12 & $\mathrm{CrM}$ & $5.42 \pm 0.5$ & $5.41 \pm 0.5$ & $5.35 \pm 0.7$ & $G \times T$ & 0.64 \\
\hline \multirow[t]{3}{*}{ Hematocrit (\%) } & 9 & $K A-L$ & $48.4 \pm 3.4$ & $47.9 \pm 4.3$ & $48.1 \pm 2.9$ & Group & 0.17 \\
\hline & 12 & $\mathrm{KA}-\mathrm{H}$ & $46.5 \pm 3.2$ & $47.0 \pm 2.8$ & $47.4 \pm 1.8$ & Time & 0.96 \\
\hline & 12 & $\mathrm{CrM}$ & $45.9 \pm 2.3$ & $46.1 \pm 2.5$ & $45.2 \pm 5.4$ & $G \times T$ & 0.65 \\
\hline \multirow[t]{3}{*}{ Hemoglobin $(\mathrm{g} / \mathrm{dl})$} & 9 & $K A-L$ & $16.0 \pm 1.6$ & $16.0 \pm 1.6$ & $16.0 \pm 1.2$ & Group & 0.21 \\
\hline & 12 & $\mathrm{KA}-\mathrm{H}$ & $15.2 \pm 1.2$ & $15.7 \pm 1.0$ & $15.6 \pm 0.7$ & Time & 0.60 \\
\hline & 12 & $\mathrm{CrM}$ & $15.1 \pm 0.9$ & $15.2 \pm 1.1$ & $14.9 \pm 2.0$ & $G \times T$ & 0.62 \\
\hline \multirow[t]{3}{*}{ MCV (fL) } & 9 & $K A-L$ & $89.0 \pm 2.8$ & $88.9 \pm 2.9$ & $88.3 \pm 2.8$ & Group & 0.10 \\
\hline & 12 & $\mathrm{KA}-\mathrm{H}$ & $91.1 \pm 3.5$ & $90.8 \pm 3.1$ & $90.7 \pm 3.6$ & Time & 0.03 \\
\hline & 12 & $\mathrm{CrM}$ & $85.4 \pm 9.2$ & $85.7 \pm 9.5$ & $85.0 \pm 9.1$ & $G \times T$ & 0.56 \\
\hline \multirow[t]{3}{*}{ MCH (pg/cell) } & 9 & $K A-L$ & $29.4 \pm 1.5$ & $29.6 \pm 1.2$ & $29.3 \pm 1.2$ & Group & 0.34 \\
\hline & 12 & $\mathrm{KA}-\mathrm{H}$ & $29.8 \pm 1.6$ & $30.2 \pm 1.5$ & $28.4 \pm 4.9$ & Time & 0.20 \\
\hline & 12 & $\mathrm{CrM}$ & $28.1 \pm 3.5$ & $28.3 \pm 3.7$ & $27.9 \pm 3.3$ & $G \times T$ & 0.44 \\
\hline \multirow[t]{3}{*}{$\mathrm{MCHC}(\mathrm{g} / \mathrm{dl})$} & 9 & $K A-L$ & $33.0 \pm 1.3$ & $33.3 \pm 0.9$ & $33.2 \pm 0.9$ & Group & 0.73 \\
\hline & 12 & $\mathrm{KA}-\mathrm{H}$ & $32.8 \pm 0.9$ & $33.3 \pm 0.8$ & $32.9 \pm 0.6$ & Time & 0.22 \\
\hline & 12 & $\mathrm{CrM}$ & $32.9 \pm 1.1$ & $32.9 \pm 1.3$ & $32.9 \pm 0.8$ & $G \times T$ & 0.68 \\
\hline \multirow[t]{3}{*}{ RBCDW (\%) } & 9 & $K A-L$ & $13.0 \pm 0.5$ & $13.0 \pm 0.9$ & $12.9 \pm 0.7$ & Group & 0.34 \\
\hline & 12 & $\mathrm{KA}-\mathrm{H}$ & $13.8 \pm 1.1$ & $13.7 \pm 1.0$ & $13.5 \pm 1.5$ & Time & 0.41 \\
\hline & 12 & $\mathrm{CrM}$ & $13.7 \pm 1.4$ & $13.7 \pm 1.7$ & $13.6 \pm 1.6$ & $G \times T$ & 0.92 \\
\hline \multirow[t]{3}{*}{ Platelet Count $\left(\times 10^{3} / \mathrm{ul}\right)$} & 9 & $K A-L$ & $266 \pm 45$ & $266 \pm 52$ & $280 \pm 45$ & Group & 0.12 \\
\hline & 12 & $\mathrm{KA}-\mathrm{H}$ & $253 \pm 54$ & $248 \pm 62$ & $269 \pm 65$ & Time & 0.32 \\
\hline & 12 & CrM & $222 \pm 69$ & $222 \pm 74$ & $216 \pm 65$ & $G \times T$ & 0.48 \\
\hline
\end{tabular}


increasing muscle creatine retention, body composition, strength, and/or anaerobic capacity than supplementing the diet with creatine monohydrate $(20 \mathrm{~g} / \mathrm{d}$ for 7 -days and $5 \mathrm{~g} / \mathrm{d}$ for 21-days). Additionally, the study was undertaken to determine whether supplementing the diet with recommended or equivalent creatine doses of a purported buffered form of creatine was associated with fewer side effects in comparison to creatine monohydrate. Results of the present study clearly show that supplementing the diet with a purported buffered form of creatine is not a more efficacious and/or a safer form of creatine to consume than creatine monohydrate.

According to product claims [28,30], KA is "up to ten times more powerful than ordinary Creatine". The rationale for this contention is based on experiments reported in a patent [29] and/or on the manufacturer's website $[28,30]$ which indicates that KA has less conversion of creatine to creatinine in fluid over time compared to creatine monohydrate. This is despite the fact that studies show that creatine monohydrate is not significantly degraded to creatinine during the normal digestive process and nearly $99 \%$ of creatine monohydrate that is orally ingested is either taken up by tissue or excreted in the urine $[1-3,18,21]$. Because of this fact, an accepted method of assessing whole body creatine retention has been to subtract daily urinary creatine excretion from daily dietary intake of creatine [32,33,45-47]. Additionally, while it is true that generally the lower the $\mathrm{pH}$ and higher the temperature, the greater conversion of creatine to creatinine, studies show that this process takes several days to occur at significant levels even when creatine is exposed to low $\mathrm{pH}$ environments $[1,19,48]$. As described in a recent review [1], the degradation of creatine can be reduced or even halted by either lowering the $\mathrm{pH}$ to under 2.5 or increasing the $\mathrm{pH}$. A very high $\mathrm{pH}$ results in the deprotonation of the acid group, thereby slowing down the degradation process by making it more difficult for the intramolecular cyclization of creatine to creatinine. However, a very low $\mathrm{pH}$ (as is the case in the stomach) results in the protonation of the amide function of the creatine molecule, thereby preventing the intramolecular cyclization of creatine to creatinine [1]. This is the reason that the conversion of creatine to creatinine in the gastrointestinal tract has been reported to be minimal regardless of transit time $[7,18,20]$. Thus, on the surface, the KA manufacturer's claims that creatine monohydrate is degraded to creatinine in large amounts after oral ingestion and that a "buffered" or " $p H$-correct" would significantly reduce this effect once consumed and thereby promote greater uptake of creatine in the muscle is inconsistent with available literature on creatine [1].

Results of the present study do not support claims that a large amount of creatine monohydrate was converted to creatinine during the digestive process and thereby resulted in less of an increase in muscle creatine than KA. In this regard, while serum creatinine levels increased to a greater degree in the KA-H and CrM groups that ingested larger amounts of creatine, the 0.1 $0.2 \mathrm{mg} / \mathrm{dL}$ greater increase observed in creatinine compared to the KA-L group was well within normal limits (i.e., $<1.28 \pm 0.20 \mathrm{mg} / \mathrm{dl}$ ) particularly for resistancetrained males. Therefore, this small change would be clinically insignificant. Additionally, a significant increase from baseline in serum creatinine was also observed in the KA-L and KA-H groups despite claims that KA completely prevents the conversion of creatine to creatinine. These findings do not support contentions that $\mathrm{CrM}$ is degraded to creatinine in large amounts or that $\mathrm{KA}$ is not converted to creatinine at all.

Previous research has shown that ingestion of $20 \mathrm{~g} / \mathrm{d}$ of CrM for 5-7 days can increase muscle creatine content $10-40 \%$ after $5-7 \mathrm{~d}$ of supplementation $[1,4-8,10]$. Prolonged low-dose ingestion of CrM (e.g., $2-3 \mathrm{~g} / \mathrm{d}$ for 4-6 weeks) has also been reported to increase muscle creatine content in a similar manner as loading strategies $[4,7,8]$. The manufacturer of KA claims that ingesting $1.5 \mathrm{~g}$ of $\mathrm{KA}$ is equivalent to ingesting 10-15 $\mathrm{g}$ of CrM [28]. If this were true, those ingesting recommended levels of KA (1.5 g/d for 28-days) should experience a similar increase in muscle creatine as those participants ingesting recommended loading $(20 \mathrm{~g} / \mathrm{d}$ for 7-days) and maintenance doses (5 g/d for 21-days) of CrM. Results of the present study indicated that supplementing the diet with manufacturer's recommended levels of KA $(1.5 \mathrm{~g} / \mathrm{d})$ did not increase muscle free creatine content to the same degree as loading and maintenance doses of CrM. In fact, although no overall group effect was observed among the three groups studied $(\mathrm{p}=0.14)$, pairwise comparison of the mean group change from baseline in the KA-L group was 11 times less than the change observed following CrM supplementation (KA-L $-1.1 \pm 4.3$, CrM $11.2 \pm 4.3 \mathrm{mmol} / \mathrm{kg}$ DW $[$ mean $\pm \mathrm{SEM}], \mathrm{p}=0.053)$. After 28-days of supplementation, muscle free creatine content in the KA-L group was increased by $4.71 \pm 27.0 \mathrm{mmol} / \mathrm{kg} \mathrm{DW}$ compared to $22.3 \pm 21.0 \mathrm{mmol} / \mathrm{kg} \mathrm{DW}$ in the CrM group representing a 4.7 fold less effect of KA supplementation than CrM when comparing recommended levels. Consequently, results of the present study do not support claims that ingesting 1.5 grams of KA is as effective as ingesting 10-15 grams of creatine monohydrate. Even when participants ingested creatine equivalent amounts of KA and CrM (i.e., $20 \mathrm{~g} / \mathrm{d}$ for 7 -days and $5 \mathrm{~g} / \mathrm{d}$ for 21 -days), KA did not promote greater increases in muscle free creatine. In fact, while not significantly different, changes in muscle creatine in the KA-H group were more than two times less than the changes observed in the CrM group 
(KA-H 9.07 $\pm 23.2 ; \quad$ CrM $22.3 \pm 21.0 \mathrm{mmol} / \mathrm{kg}$ DW). Thus, results of the present study do not support claims that ingesting a purported buffered form of creatine is more effective in increasing muscle creatine content than creatine monohydrate.

While some may argue that since there is generally large variability in measuring muscle phosphagen levels and we were unable to obtain reliable $\mathrm{PCr}$ measurements, it is difficult to make a definitive conclusion about the effects of KA on muscle creatine content based on measuring muscle free content alone. However, present findings also provide no support for claims that KA supplementation is "up to ten times more powerful than ordinary Creatine." In this regard, while time effects were observed in training adaptations, supplementing the diet with KA (at recommended or creatine equivalent loading and maintenance doses) did not promote statistically greater gains in fat free mass, $1 \mathrm{RM}$ strength, or anaerobic sprint performance capacity compared to CrM. At best, one can conclude that ingesting recommended and creatine equivalent loading and maintenance amounts of KA resulted in similar training adaptations as creatine monohydrate supplementation at recommended loading and maintenance levels. However, results of the present investigation provide no evidence to support claims that KA is "the world's most potent creatine" [28].

Further, results of the present investigation provided no evidence that KA is a safer form of creatine to consume at either lower recommended levels or higher creatine equivalent doses compared to normal loading and maintenance doses of creatine monohydrate. In this regard, there were no significant differences observed among groups in BIA determined total body water or serum electrolyte status. Likewise, no cramping or other side effects were reported. These findings are consistent with previous studies that have indicated that creatine supplementation does not promote dehydration and/or cramping [9,21-26]. There were also no significant differences observed among groups in serum lipids (TCHL, HDL, TCHL:HDL ratio, TRIG) or blood glucose. Serum LDL decreased slightly in response to creatine loading in the CrM group but returned to baseline after ingesting maintenance doses of CrM suggesting these changes were transient. Additionally, no significant differences were observed among groups in markers of catabolism (BUN, BUN:CRN, AST, ALT, Total Protein, TBIL), markers of bone status (bone mineral content, ALB, GLOB, ALB:GLOB, calcium, ALK) or whole blood markers (WBC, RBC, Hematocrit, Hemoglobin, MCV, MCH, MCHC, RBCDW, platelet counts). Moreover, values remained within normal levels for active individuals. These findings are consistent with other studies that have examined the safety of creatine supplementation in active individuals $[1,3,21,26,27,38]$. Consequently, present findings do not support claims that $\mathrm{KA}$ is a safer form of creatine to ingest than creatine monohydrate.

\section{Conclusion}

In summary, supplementation of the diet with recommended doses of a purported buffered form of creatine $(1.5 \mathrm{~g} / \mathrm{d})$ for 28 -days or equivalent loading $(20 \mathrm{~g} / \mathrm{d}$ for 7 days) and maintenance doses (5 g/d for 21-days) of CrM did not promote greater increases in muscle creatine content or training adaptations in comparison to creatine monohydrate (20 g/d for 7-days, $5 \mathrm{~g} / \mathrm{d}$ for 21 -days). Additionally, there was no evidence to support claims that the buffered form of creatine was associated with fewer side effects or was a safer form of creatine to consume than creatine monohydrate. While it could be argued that supplementing the diet with any form of creatine may provide some health and/or ergogenic benefits over time as long as it delivers sufficient amounts of creatine to increase muscle creatine content; present findings do not support claims that KA is a more efficacious and/or safer form of creatine than creatine monohydrate. With this said, some limitations of this study should be noted. For example, this study did not have a control group and depended on participants to selfreport side effects. Therefore, while the safety profile of short and long-term creatine monohydrate supplementation has been well established, safety and efficacy could only be compared to ingesting different levels and forms of creatine and not controls. There is also variability in conducting muscle and blood assays as well as variability in conducting performance tests. In some instances, large mean differences among groups were either not statistically significant or only approached significance. It is possible that some of these differences would have been significant if a control group was included in the study design and/or more subjects were studied to increase statistical power. Nevertheless, results from the present study do not support claims that KA is a more efficacious and/or safer form of creatine to consume than creatine monohydrate.

\section{Competing interests}

AlzChem AG (Trostberg, Germany) provided funding for this study through a research grant to Texas A\&M University. All researchers involved independently collected, analyzed, and interpreted the results from this study and have no financial interests concerning the outcome of this investigation. RBK has received grants as Principal Investigator through institutions with which he has been affiliated to conduct exercise and nutrition related research, has served as a legal and scientific consultant, and currently serves as a scientific consultant for Woodbolt International (Bryan, TX). Remaining coauthors have no competing interests to declare. Data from this study have been presented at the International Society of Sports Nutrition Annual meeting and have not been submitted for publication to any other journals. Publication of these findings should not be viewed as endorsement by the investigators or their institutions of the nutrients investigated. 


\section{Authors' contributions}

ARJ served as the study coordinator, oversaw all testing, and assisted in data analysis and writing of the manuscript. JMO assisted in data collection and statistical analysis. AS assisted with data collection. EG assisted with data collection and reviewed and approved nutritional records as the studies' registered dietitian. JF and SR supervised the biopsy procedures. MG assisted in experimental design, data analysis, and manuscript preparation. KK supervised muscle assays and CM served as a collaborating scientist. CR served as lab coordinator and oversaw data collection and quality control of the study. RBK served as Principal Investigator and contributed to the design of the study, statistical analysis, manuscript preparation, and procurement of external funding. All authors read and approved the final manuscript.

\section{Funding}

Supported by AlzChem AG, Germany.

\section{Acknowledgements}

We would like to thank the individuals who participated in this study as well as all of the students and administrative support staff at Texas A\&M University that assisted in conducting this study. We would also like thank Dr. John Thaden for clinical chemistry technical support and Dr. J.P. Bramhall for providing medical supervision for this study. "All authors have approved manuscript for submission."

\section{Author details}

'Department of Health and Kinesiology, Exercise and Sport Nutrition Laboratory, Texas A\&M University, College Station, TX 77843-4243, USA. ${ }^{2}$ Department of Sports Medicine and Nutrition, Neuromuscular Research Laboratory, University of Pittsburgh, Pittsburgh, PA 15203, Oakland. ${ }^{3}$ Department of Health and Kinesiology, Muscle Biology Laboratory, Texas A\&M University, College Station, TX 77843-4243, USA. ${ }^{4}$ Department of Health and Kinesiology, Human Countermeasures Laboratory, Texas A\&M University, College Station, TX 77843-4243, USA. ${ }^{5}$ Department of Systems Biology and Translational Medicine, Texas A\&M Health Science Center, College Station, TX 77843-1114, USA.

Received: 3 August 2012 Accepted: 6 September 2012 Published: 13 September 2012

\section{References}

1. Jager R, Purpura M, Shao A, Inoue T, Kreider RB: Analysis of the efficacy, safety, and regulatory status of novel forms of creatine. Amino Acids 2011, 40:1369-1383.

2. Kreider RB, Wilborn CD, Taylor L, Campbell B, Almada AL, Collins R, Cooke M, Earnest CP, Greenwood M, Kalman DS, et al: ISSN exercise \& sport nutrition review: research \& recommendations. J Int Soc Sports Nutr 2010, 7:7.

3. Kreider RB, Jung YP: Creatine supplementation in exercise, sport, and medicine. Journal of Exercise Nutrition and Biochemistry 2011, 15:53-69.

4. Greenhaff P, Constantin-Teodosiu D, Casey A, Hultman E: The effect of oral creatine supplementation on skeletal muscle ATP degradation during repeated bouts of maximal voluntary exercise in man. J Physiol 1994, 476:84.

5. Greenhaff PL, Bodin K, Soderlund K, Hultman E: Effect of oral creatine supplementation on skeletal muscle phosphocreatine resynthesis. Am J Physiol 1994, 266:E725-E730.

6. Greenhaff PL, Casey A, Short AH, Harris R, Soderlund K, Hultman E: Influence of oral creatine supplementation of muscle torque during repeated bouts of maximal voluntary exercise in man. Clin Sci (Lond) 1993, 84:565-571.

7. Harris RC, Soderlund K, Hultman E: Elevation of creatine in resting and exercised muscle of normal subjects by creatine supplementation. Clin Sci (Colch) 1992, 83:367-374.

8. Hultman E, Soderlund K, Timmons JA, Cederblad G, Greenhaff PL: Muscle creatine loading in men. J Appl Physiol 1996, 81:232-237.

9. Kreider RB, Ferreira M, Wilson M, Grindstaff P, Plisk S, Reinardy J, Cantler E, Almada AL: Effects of creatine supplementation on body composition, strength, and sprint performance. Med Sci Sports Exerc 1998, 30:73-82.

10. Volek JS, Duncan ND, Mazzetti SA, Staron RS, Putukian M, Gomez AL, Pearson DR, Fink WJ, Kraemer WJ: Performance and muscle fiber adaptations to creatine supplementation and heavy resistance training. Med Sci Sports Exerc 1999, 31:1147-1156.

11. Braissant $\mathrm{O}$, Henry $\mathrm{H}$, Beard $\mathrm{E}, \mathrm{Uldry} \mathrm{J}$ : Creatine deficiency syndromes and the importance of creatine synthesis in the brain. Amino Acids 2011, 40:1315-1324

12. Candow DG: Sarcopenia: current theories and the potential beneficial effect of creatine application strategies. Biogerontology 2011, 12:273-281.

13. Gualano B, Roschel H, Lancha-Jr AH, Brightbill CE, Rawson ES: In sickness and in health: the widespread application of creatine supplementation. Amino Acids 2011, 43:519-229.

14. Klopstock T, Elstner M, Bender A: Creatine in mouse models of neurodegeneration and aging. Amino Acids 2011, 40:1297-1303.

15. Rawson ES, Venezia AC: Use of creatine in the elderly and evidence for effects on cognitive function in young and old. Amino Acids 2011, 40:1349-1362

16. Tarnopolsky MA: Creatine as a therapeutic strategy for myopathies. Amino Acids 2011, 40:1397-1407.

17. Wallimann T, Tokarska-Schlattner M, Schlattner U: The creatine kinase system and pleiotropic effects of creatine. Amino Acids 2011, 40:1271-1296

18. Deldicque L, Decombaz J, Zbinden Foncea H, Vuichoud J, Poortmans JR, Francaux M: Kinetics of creatine ingested as a food ingredient. Eur J Appl Physiol 2008, 102:133-143.

19. Ganguly S, Jayappa S, Dash AK: Evaluation of the stability of creatine in solution prepared from effervescent creatine formulations. AAPS PharmSciTech 2003, 4:E25.

20. Persky AM, Brazeau GA, Hochhaus G: Pharmacokinetics of the dietary supplement creatine. Clin Pharmacokinet 2003, 42:557-574.

21. Buford TW, Kreider RB, Stout JR, Greenwood M, Campbell B, Spano M, Ziegenfuss T, Lopez H, Landis J, Antonio J: International Society of Sports Nutrition position stand: creatine supplementation and exercise. J Int Soc Sports Nutr 2007, 4:6.

22. Dalbo VJ, Roberts MD, Stout JR, Kerksick CM: Putting to rest the myth of creatine supplementation leading to muscle cramps and dehydration. $\mathrm{Br}$ J Sports Med 2008, 42:567-573.

23. Greenwood M, Greenwood L, Kreider R, Stahura K: Creatine supplementation does not increase perceptions of fatigue or adversely affect health status during three a day training. J Athletic Train 2002, 37:582.

24. Greenwood M, Kreider RB, Greenwood L, Byars A: Cramping and Injury Incidence in Collegiate Football Players Are Reduced by Creatine Supplementation. J Athl Train 2003, 38:216-219.

25. Greenwood M, Kreider RB, Melton C, Rasmussen C, Lancaster S, Cantler E, Milnor P, Almada A: Creatine supplementation during college football training does not increase the incidence of cramping or injury. Mol Cell Biochem 2003, 244:83-88.

26. Kreider RB, Melton C, Rasmussen C, Greenwood M, Lancaster S, Cantler E, Milnor P, Almada A: Long-term creatine supplementation does not significantly affect clinical markers of health in athletes. Mol Cell Biochem 2003, 244:95-104.

27. Kim HJ, Kim CK, Carpentier A, Poortmans JR: Studies on the safety of creatine supplementation. Amino Acids 2011, 40:1409-1418.

28. All American EFX: Kre-Alkalyn - The World's Most Potent Creatine. http:// krealkalyn.com/.

29. Golini JM: Oral creatine supplement and method for making same. US: 6,399,661 B1; Issue date, June 4, 2002.

30. All American Pharmaceutical: Kre-Alkalyn Research Booklet. http://krealkalyn. com/images/downloads/kre-alkalyn_research_booklet.pdf.

31. Tallon MJ, Child R: Kre-alkalyn ${ }^{\circledR}$ supplementation has no beneficial effect on creatine-to-creatinine conversion rates. Las Vegas, NV: International Society of Sports Nutrition Annual Conference; 2007.

32. Greenwood M, Kreider R, Earnest C, Rasmussen C, Almada A: Differences in creatine retention among three nutritional formulations of oral creatine supplements. Journal of Exercise Physiology: Online 2003, 6:37-43.

33. Greenwood M, Kreider RB, Rasmussen C, Almada AL, Earnest CP: D-Pinitol augments whole body creatine retention in man. J Exerc Physiol Online 2001, 4:41-47.

34. Grindstaff PD, Kreider R, Bishop R, Wilson M, Wood L, Alexander C, Almada A: Effects of creatine supplementation on repetitive sprint performance and body composition in competitive swimmers. Int I Sport Nutr 1997, 7:330-346. 
35. Kerksick CM, Rasmussen C, Lancaster S, Starks M, Smith P, Melton C, Greenwood M, Almada A, Kreider R: Impact of differing protein sources and a creatine containing nutritional formula after 12 weeks of resistance training. Nutrition 2007, 23:647-656.

36. Kreider R, Willoughby DS, Greenwood M, Parise G, Payne D, Tarnopolsky M Effects of serum creatine supplementation on muscle creatine content. Journal of Exercise Physiology: online 2003, 6:24-33.

37. Kreider RB, Klesges B, Harmon K, Grindstaff P, Ramsey L, Bullen D, Wood L, Li Y, Almada A: Effects of ingesting supplements designed to promote lean tissue accretion on body composition during resistance training. Int J Sport Nutr 1996, 6:234-246.

38. Kreider RB, Klesges RC, Lotz D, Davis M, Cantler E, Harmon-Clayton K, Dudley R, Grindstaff P, Ramsey L, Bullen D, et al: Effects of nutritional supplementation during off-season college football training on body composition and strength. Journal of Exercise Physiology Online 1999, 2:24-39.

39. Spillane M, Schoch R, Cooke M, Harvey T, Greenwood M, Kreider R, Willoughby DS: The effects of creatine ethyl ester supplementation combined with heavy resistance training on body composition, muscle performance, and serum and muscle creatine levels. J Int Soc Sports Nutr 2009, 6:6.

40. Lohman M, Tallroth K, Kettunen JA, Marttinen MT: Reproducibility of dualenergy x-ray absorptiometry total and regional body composition measurements using different scanning positions and definitions of regions. Metabolism 2009, 58:1663-1668.

41. Almada A, Kreider R, Ransom J, Rasmussen C, Tutko R, Milnor P. Comparison of the reliability of repeated whole body DEXA scans to repeated spine and hip scans. J Bone Miner Res 1999, 14:SA243.

42. Evans WJ, Phinney SD, Young VR: Suction applied to a muscle biopsy maximizes sample size. Med Sci Sports Exerc 1982, 14:101-102.

43. Harris RC, Hultman E, Nordesjo LO: Glycogen, glycolytic intermediates and high-energy phosphates determined in biopsy samples of musculus quadriceps femoris of man at rest. Methods and variance of values. Scand I Clin Lab Invest 1974, 33:109-120.

44. Kerksick CM, Wilborn CD, Campbell Bl, Roberts MD, Rasmussen C Greenwood M, Kreider RB: Early-phase adaptations to a split-body, linear periodization resistance training program in college-aged and middleaged men. J Strength Cond Res 2009, 23:962-971.

45. Oopik V, Paasuke M, Timpmann S, Medijainen L, Ereline J, Gapejeva J: Effects of creatine supplementation during recovery from rapid body mass reduction on metabolism and muscle performance capacity in well-trained wrestlers. J Sports Med Phys Fitness 2002, 42:330-339

46. Steenge GR, Simpson EJ, Greenhaff PL: Protein- and carbohydrate-induced augmentation of whole body creatine retention in humans. J Appl Physiol 2000, 89:1165-1171.

47. Kerksick CM, Willborn CD, Campbell WI, Harvey TM, Marcello BM, Roberts MD, Parker AG, Byars AG, Greenwood LD, Almada AL, et al: The effects of creatine monohydrate supplementation with and without D-pinitol on resistance training adaptations. J Strength Cond Res 2009, 23:2673-2682.

48. Dash AK, Sawhney A: A simple LC method with UV detection for the analysis of creatine and creatinine and its application to several creatine formulations. J Pharm Biomed Anal 2002, 29:939-945.

doi:10.1186/1550-2783-9-43

Cite this article as: Jagim et al:: A buffered form of creatine does not promote greater changes in muscle creatine content, body composition, or training adaptations than creatine monohydrate. Journal of the International Society of Sports Nutrition 2012 9:43.

\section{Submit your next manuscript to BioMed Central and take full advantage of:}

- Convenient online submission

- Thorough peer review

- No space constraints or color figure charges

- Immediate publication on acceptance

- Inclusion in PubMed, CAS, Scopus and Google Scholar

- Research which is freely available for redistribution

Submit your manuscript at www.biomedcentral.com/submit
Ciomed Central 